\title{
Modeling kinetic partitioning of secondary organic aerosol and size distribution dynamics: representing effects of volatility, phase state, and particle-phase reaction
}

\author{
R. A. Zaveri ${ }^{1}$, R. C. Easter $^{1}$, J. E. Shilling ${ }^{1}$, and J. H. Seinfeld ${ }^{2}$ \\ ${ }^{1}$ Atmospheric Sciences and Global Change Division, Pacific Northwest National Laboratory, Richland, WA, USA \\ ${ }^{2}$ Division of Chemistry and Chemical Engineering and Division of Engineering and Applied Science, California Institute of \\ Technology, Pasadena, CA, USA
}

Correspondence to: R. A. Zaveri (rahul.zaveri@pnnl.gov)

Received: 12 October 2013 - Published in Atmos. Chem. Phys. Discuss.: 4 November 2013

Revised: 22 February 2014 - Accepted: 18 March 2014 - Published: 27 May 2014

\begin{abstract}
This paper describes and evaluates a new framework for modeling kinetic gas-particle partitioning of secondary organic aerosol (SOA) that takes into account diffusion and chemical reaction within the particle phase. The framework uses a combination of (a) an analytical quasisteady-state treatment for the diffusion-reaction process within the particle phase for fast-reacting organic solutes, and (b) a two-film theory approach for slow- and nonreacting solutes. The framework is amenable for use in regional and global atmospheric models, although it currently awaits specification of the various gas- and particle-phase chemistries and the related physicochemical properties that are important for SOA formation. Here, the new framework is implemented in the computationally efficient Model for Simulating Aerosol Interactions and Chemistry (MOSAIC) to investigate the competitive growth dynamics of the Aitken and accumulation mode particles. Results show that the timescale of SOA partitioning and the associated size distribution dynamics depend on the complex interplay between organic solute volatility, particle-phase bulk diffusivity, and particlephase reactivity (as exemplified by a pseudo-first-order reaction rate constant), each of which can vary over several orders of magnitude. In general, the timescale of SOA partitioning increases with increase in volatility and decrease in bulk diffusivity and rate constant. At the same time, the shape of the aerosol size distribution displays appreciable narrowing with decrease in volatility and bulk diffusivity and increase in rate constant. A proper representation of these physicochemical processes and parameters is needed in the next generation
\end{abstract}

models to reliably predict not only the total SOA mass, but also its composition- and number-diameter distributions, all of which together determine the overall optical and cloudnucleating properties.

\section{Introduction}

Submicron sized atmospheric aerosol particles are typically composed of ammonium, sulfate, nitrate, black carbon, organics, sea salt, mineral dust, and water that are often internally mixed with each other in varying proportions. Depending on their dry state composition and overall hygroscopicity, aerosol particles in the size range $0.03-0.1 \mu \mathrm{m}$ (dry diameter) and larger may act as cloud condensation nuclei (CCN) (Dusek et al., 2006; Gunthe et al., 2009, 2011) while those larger than $0.1 \mu \mathrm{m}$ (wet diameter) efficiently scatter solar radiation. Aerosol number and composition size distributions, therefore, together hold the key to determining its overall climate-relevant properties.

Organic compounds constitute $20-90 \%$ of the submicron aerosol mass and are thought to play a vital role in both the direct and indirect aerosol radiative forcing of climate (Kanakidou et al., 2005). While primary organic aerosols (POA) from fossil fuel combustion and biomass burning are directly emitted into the submicron size range, the dominant source of organic aerosols is secondary, which involves gas-to-particle conversion of many different volatile organic compounds (VOCs) of both anthropogenic and biogenic ori- 
gin (Zhang et al., 2007). Furthermore, biogenic VOCs are estimated to be the dominant source of secondary organic aerosol (SOA), but their formation appears to be strongly influenced by anthropogenic emissions (Weber et al., 2007; Hoyle et al., 2011; Shilling et al., 2013). Organic vapors are also implicated in facilitating new particle formation initiated by sulfuric acid (Kulmala et al., 2004; Paasonen et al., 2010; Kuang et al., 2012) and are found to play a crucial role in the subsequent growth of the nanoparticles (Smith et al., 2008; Pierce et al., 2011, 2012; Riipinen et al., 2011; Winkler et al., 2012). Thus, the majority of the optically and $\mathrm{CCN}$-active particles are produced through the growth of smaller particles by condensation of SOA species (Riipinen et al., 2012). It is therefore necessary that climate models be able to accurately simulate not just the total organic mass loading, but also the evolution of aerosol number and composition size distributions resulting from SOA formation.

It is broadly understood that, in cloud-free air, SOA forms via three possible mechanisms: (1) effectively irreversible condensation of very low volatility organic vapors produced by gas-phase oxidation (Donahue et al., 2011; Pierce et al., 2011); (2) volume-controlled reversible absorption of semivolatile organic vapors into preexisting particle organic phase according to Raoult's law (Pankow, 1994) or into preexisting particle aqueous phase according to Henry's law (Carlton and Turpin, 2013); and (3) absorption of semivolatile and volatile organic vapors into preexisting aerosol followed by particle-phase reactions to form effectively nonvolatile products such as organic salts (Smith et al., 2010), oligomers, organic acids and other high molecular weight oxidation products (Gao et al., 2004; Kalberer et al., 2004; Heaton et al., 2007; Nozière et al., 2007; Ervens et al., 2010; Wang et al., 2010; Hall and Johnston, 2011; Liu et al., 2012), hemiacetals (Kroll et al., 2008; Ziemann et al., 2012; Shiraiwa et al., 2013a), and organosulfates (Surratt et al., 2007; Zaveri et al., 2010). Recently, Liu et al. (2014) presented an exact analytical solution to the diffusion-reaction problem in the aqueous phase. While aqueous-phase chemistry in cloud droplets is also a potential source of SOA (Carlton et al., 2008; Ervens et al., 2008; Mouchel-Vallon et al., 2013), this route is not considered in the present study. Several recent studies also indicate that the phase state of SOA may be viscous semisolids under dry and moderate relative humidity conditions (Virtanen et al., 2010; Vaden et al., 2011; Saukko et al., 2012), with very low particle-phase bulk diffusivities (Abramson et al., 2013; Renbaum-Wolff et al., 2013). The timescales of SOA partitioning (Shiraiwa and Seinfeld, 2012b) and the resulting aerosol size distributions from these three mechanisms can be quite different, and the particle-phase state is expected to modulate the growth dynamics as well.

Riipinen et al. (2011) analyzed the evolution of ambient aerosol size distributions with a simplified model consisting of mechanisms \#1 and \#2 for liquid particles and concluded that both mechanisms were roughly equally needed to explain the observed aerosol growth. Perraud et al. (2012) studied the gas-particle partitioning of organic nitrate vapors formed from simultaneous oxidation of $a$-pinene by $\mathrm{O}_{3}$ and $\mathrm{NO}_{3}$ in a flow tube reactor. Their model analysis suggested that, despite being semivolatile, the organic nitrate species had effectively irreversibly condensed (mechanism \#1) as their adsorbed layers were continuously "buried" in presumably semisolid particles by other incoming organic vapors. In a theoretical study, Zhang et al. (2012) contrasted the aerosol size distributions produced by mechanisms \#1 and \#2 for liquid particles and illustrated the roles of solute volatility and vapor source rate in shaping the size distribution via mechanism \#2. In another theoretical study, Shiraiwa and Seinfeld (2012b) used the detailed multilayer kinetic flux model KM-GAP (Shiraiwa et al., 2012a; based on the PRA model framework of Pöschl-Rudich-Ammann, 2007) to investigate the effect of phase state on SOA partitioning. They showed that the timescale for gas-particle equilibration via mechanism \#2 increases from hours to days for organic aerosol associated with semisolid particles, low volatility, large particle size, and low mass loadings. More recently, Shiraiwa et al. (2013a) studied SOA formation from photooxidation of dodecane in the presence of dry ammonium sulfate seed particles in an environmental chamber. Their analysis of the observed aerosol size distribution evolution with the KM-GAP model revealed the presence of particle-phase reactions (i.e., mechanism \#3), which contributed more than half of the SOA mass, with the rest formed via mechanism \#2. Furthermore, the physical state of the SOA was assumed to be semisolid with an average bulk diffusivity of $10^{-12} \mathrm{~cm}^{2} \mathrm{~s}^{-1}$, and the particle-phase reactions were predicted to occur mainly on the surface.

While valuable insights into the effect of phase state on SOA formation have emerged from several recent studies, a comprehensive, quantitative analysis of the effects of organic solute volatility, phase state, and particle-phase reaction on aerosol growth dynamics has not yet been performed. Additionally, there is a lack of a kinetic SOA partitioning treatment for semisolids (with particle-phase chemical reactions) that is amenable for use in regional and global atmospheric models. The present work addresses both these topics. The paper is structured as follows. In Sect. 2, we examine the dynamics of diffusion and reaction in a spherical particle with an analytical solution to the problem. In Sect. 3, we extend the MOSAIC (Model for Simulating Aerosol Interactions and Chemistry) aerosol model (Zaveri et al., 2008) to include a new framework for kinetic gas-particle partitioning of SOA and evaluate it against a rigorous model based on the finite-difference approach. The new framework uses a combination of (a) an analytical quasi-steady-state treatment for the diffusion-reaction process within the particle phase for fast-reacting species, and (b) a two-film theory approach for slow- and nonreacting organic solutes. The framework is amenable for eventual use in regional and global climate models, although it currently awaits specification of the 


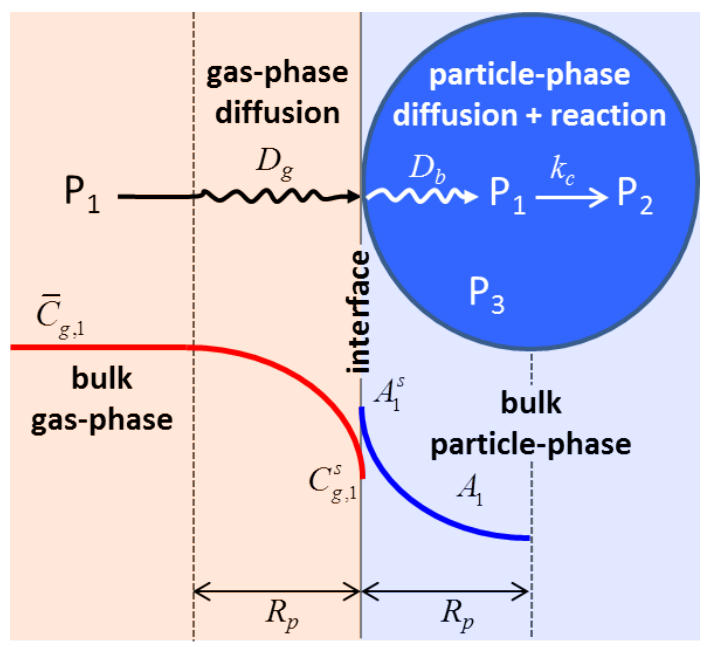

Figure 1. Schematic of the gas-particle mass-transfer process, with both diffusion and reaction occurring inside the particle phase.

actual particle-phase reactions that are important for SOA formation. In Sect. 4, we apply the model to evaluate the timescale of SOA partitioning and the associated evolution of the number and composition size distributions for a range of solute volatilities, bulk diffusivities, and particle-phase reaction rates. We close with a summary of our findings and their implications.

\section{Dynamics of diffusion and reaction within a particle}

Consider an organic solute $i$ that diffuses from the gas phase to a single spherical organic aerosol particle and reacts irreversibly with a pseudo-first-order rate constant $k_{\mathrm{c}}\left(\mathrm{s}^{-1}\right)$ as it diffuses inside the particle. This process is illustrated in Fig. 1 using three species $\left(P_{1}, P_{2}\right.$, and $\left.P_{3}\right)$ for simplicity. The organic solute $P_{1}$ diffuses and reacts to form a nonvolatile species $P_{2}$ inside an organic particle (of radius $R_{\mathrm{p}}$ ) that is initially composed of a nonvolatile organic species $P_{3}$. The solute's gas-phase concentrations far away from the particle (i.e., in the bulk gas-phase) and just above the particle surface are $\bar{C}_{\mathrm{g}}$ and $\bar{C}_{\mathrm{g}}^{\mathrm{s}}\left(\mathrm{mol} \mathrm{cm}{ }^{-3}\right.$ (air)), respectively. The solute's particle-phase concentration just inside the particle surface and at any location in the bulk of the particle are denoted as $A^{\mathrm{s}}$ and $A\left(\mathrm{~mol} \mathrm{~cm}^{-3}\right.$ (particle)), respectively. The gas- and particle-phase diffusivities of the solute are $D_{\mathrm{g}}$ and $D_{\mathrm{b}}\left(\mathrm{cm}^{2} \mathrm{~s}^{-1}\right)$, respectively.

In this section we shall focus on the dynamics of diffusion and reaction inside the particle. In order to derive the timescales relevant to this problem, the particle, initially free of the organic solute (i.e., at time $t=0$ ), is assumed to be exposed to a constant concentration just inside the particle surface, $A_{i}^{\mathrm{s}}$, at all times $t>0$ (this assumption will be relaxed in Sect. 3 where we will relate the temporally changing gas-phase concentration of the solute to its particle-phase concentration). Assuming that the diffusive flux of the solute into the particle follows Fick's law, the transient partial differential equation describing the particle-phase concentration $A_{i}(r, t)$ as a function of radius $r$ and time $t$ can be written as

$\frac{\partial A_{i}(r, t)}{\partial t}=D_{\mathrm{b}, i} \frac{1}{r^{2}} \frac{\partial}{\partial r}\left(r^{2} \frac{\partial A_{i}(r, t)}{\partial r}\right)-k_{\mathrm{c}, i} A_{i}(r, t)$.

The particle is assumed to be spherically symmetrical with respect to the concentration profiles of the organic solute in the particle at any given time, so the concentration gradient at the center of the particle (i.e., $r=0$ ) is always zero. These assumptions give rise to the following initial and boundary conditions:

I.C. : $A_{i}(r, 0)=0$,

B.C. $1: A_{i}\left(R_{\mathrm{p}}, t\right)=A_{i}^{\mathrm{s}}$,

B.C. $2: \frac{\partial A_{i}(0, t)}{\partial r}=0$.

Equation (1), with conditions (Eq. 2), can be analytically solved by first solving the pure diffusion problem in the absence of reaction (Carslaw and Jaeger, 1959; Crank, 1975) and then extending the solution to the case of first-order chemical reaction using the method of Danckwerts (1951) to yield the solution

$$
\begin{aligned}
& \frac{A_{i}(r, t)}{A_{i}^{s}}=\frac{R_{\mathrm{p}}}{r} \frac{\sinh \left(q_{i} r / R_{\mathrm{p}}\right)}{\sinh \left(q_{i}\right)}+ \\
& \frac{2 R_{\mathrm{p}}}{\pi r} \sum_{n=1}^{\infty} \frac{(-1)^{n} n \sin \left(n \pi r / R_{\mathrm{p}}\right)}{\left(q_{i} / \pi\right)^{2}+n^{2}} \exp \left\{-\left(k_{\mathrm{c}, i}+\frac{n^{2} \pi^{2} D_{\mathrm{b}, i}}{R_{\mathrm{p}}^{2}}\right) t\right\},
\end{aligned}
$$

where $q_{i}$ is a dimensionless diffusion-reaction parameter defined as the ratio of the particle radius $R_{\mathrm{p}}$ to the so-called reacto-diffusive length $\sqrt{D_{\mathrm{b}, i} / k_{\mathrm{c}, i}}$ (Pöschl et al., 2007):

$q_{i}=R_{\mathrm{p}} \sqrt{\frac{k_{\mathrm{c}, i}}{D_{\mathrm{b}, i}}}$.

It should be noted that this solution assumes that $R_{\mathrm{p}}$ remains constant with time, so diffusion of additional material into the particle is relatively small (this assumption will also be relaxed in Sect. 3). It is also worth noting here that in glassy particles, the diffusion fronts of plasticzing agents (such as water) may move linearly inward, leading to a linear dependence on $R_{\mathrm{p}}$ instead of $R_{\mathrm{p}}^{2}$ in Fickian diffusion (Zobrist et al., 2011).

Now, the timescale for Fickian diffusion of the dissolved solute $i$ in the particle, $\tau_{\mathrm{da}}$, and the timescale for chemical reaction, $\tau_{\mathrm{c}}$, (Seinfeld and Pandis, 2006) are defined as

$$
\begin{aligned}
\tau_{\mathrm{da}, i} & =\frac{R_{\mathrm{p}}^{2}}{\pi^{2} D_{\mathrm{b}, i}}, \\
\tau_{\mathrm{c}, i} & =\frac{1}{k_{\mathrm{c}, i}} .
\end{aligned}
$$


The model described by these equations has been applied to investigate mass-transfer limitation to the rate of $\mathrm{SO}_{2}$ oxidation in cloud droplets (Schwartz and Freiberg, 1981; Shi and Seinfeld, 1991), for which the droplets typically exceed a $10 \mu \mathrm{m}$ diameter, with the aqueous-phase diffusivity about $10^{-5} \mathrm{~cm}^{2} \mathrm{~s}^{-1}$. Here we apply this model to analyze the effects of particle-phase reactions in organic particles of sizes ranging from $\sim 10^{-3}$ to $1 \mu \mathrm{m}$ diameter, with $D_{\mathrm{b}}$ values ranging from $<10^{-18}$ to $10^{-5} \mathrm{~cm}^{-2} \mathrm{~s}^{-1}$ (Renbaum-Wolff et al., 2013). Since the actual particle-phase reactions of various organic species and the associated rate constants are still not well defined, we use a pseudo-first-order reaction as a proxy and vary its rate constant $k_{\mathrm{c}}$ over several orders of magnitude $\left(10^{-5}-10^{-1} \mathrm{~s}^{-1}\right)$ to examine its effect on the dynamics of particle growth.

The right-hand side of Eq. (2) comprises two terms. The first term is the concentration profile at steady state with the surface concentration, while the second term describes the temporal evolution of the concentration profile. At steady state, the transient term disappears for $t \gg \tau_{\mathrm{da}}$ and $\tau_{\mathrm{c}}$. Figure 2 illustrates the relative effects of bulk diffusivity and reaction rate constant on the temporal evolution of the diffusing solute concentration profiles within a particle of diameter $D_{\mathrm{p}}=0.1 \mu \mathrm{m}$. The top row represents a liquid organic particle with a rather high bulk diffusivity, $D_{\mathrm{b}}=10^{-6} \mathrm{~cm}^{2} \mathrm{~s}^{-1}$, with (a) no reaction $\left(k_{\mathrm{c}}=0\right)$, and (b) a modest reaction rate constant, $k_{\mathrm{c}}=5 \times 10^{-4} \mathrm{~s}^{-1}$. In case (a), $\tau_{\mathrm{da}}=2.5 \mu \mathrm{s}$, and the solute attains a uniform steady-state concentration profile across the particle radius in a little over $8 \mu$ s (i.e., about $\left.4 \tau_{\mathrm{da}}\right)$. The temporal evolution of the concentration profiles in case (b) appears to be identical to case (a) despite the presence of a chemical reaction, because $\tau_{\mathrm{da}}$ is $2.5 \mu \mathrm{s}$ but $\tau_{\mathrm{c}}=2000$ s, i.e., diffusion occurs much more rapidly than reaction. In contrast, the bottom row represents a semisolid organic particle, $D_{\mathrm{b}}=10^{-15} \mathrm{~cm}^{2} \mathrm{~s}^{-1}$, with (c) no reaction, and (d) $k_{\mathrm{c}}=5 \times 10^{-4} \mathrm{~s}^{-1}$. In case (c), $\tau_{\mathrm{da}}=2533 \mathrm{~s}$ (i.e., $42 \mathrm{~min}$ ) and $\sim 160 \mathrm{~min}$ is required for the solute to attain a uniform steady-state profile. In case (d), $\tau_{\mathrm{da}}$ and $\tau_{\mathrm{c}}$ are comparable, and as a result the solute not only reaches the steady state sooner (in about $60 \mathrm{~min}$ ) than in the no-reaction case, but also the steady-state concentration profile is visibly nonuniform. This is a result of the fact that there is sufficient time for appreciable amounts of the solute to be consumed by the reaction as it diffuses towards the center of the particle.

Figure 3 illustrates the steady-state concentration profiles for a range of $k_{\mathrm{c}}$ values (from $10^{-5}$ to $0.1 \mathrm{~s}^{-1}$ ) in a particle of diameter $D_{\mathrm{p}}=0.1 \mu \mathrm{m}$ with four different $D_{\mathrm{b}}$ values: (a) $10^{-6} \mathrm{~cm}^{2} \mathrm{~s}^{-1}$, (b) $10^{-12} \mathrm{~cm}^{2} \mathrm{~s}^{-1}$, (c) $10^{-13} \mathrm{~cm}^{2} \mathrm{~s}^{-1}$, and (d) $10^{-15} \mathrm{~cm}^{2} \mathrm{~s}^{-1}$. Altogether, these cases represent twenty different combinations of $\tau_{\mathrm{da}}$ and $\tau_{\mathrm{c}}$. In case (a), $\tau_{\mathrm{da}} \ll \tau_{\mathrm{c}}$ for all the $k_{\mathrm{c}}$ values considered here, and as a result the steadystate concentration profiles are essentially uniform across the entire particle, with the consumption of the solute by chemical reaction occurring uniformly across the entire volume of the particle. In case (b), even though the particle is consid- ered to be a semisolid with $D_{\mathrm{b}}=10^{-12} \mathrm{~cm}^{-2} \mathrm{~s}^{-1}, \tau_{\mathrm{da}}$ and $\tau_{\mathrm{c}}$ become comparable only when $k_{\mathrm{c}}=0.1 \mathrm{~s}^{-1}$ (and higher). However, slower reactions produce nonuniform steady-state concentration profiles in cases (c) and (d) for $D_{\mathrm{b}}$ values of $10^{-13} \mathrm{~cm}^{2} \mathrm{~s}^{-1}$ and lower. In these cases, most of the solute is consumed near the surface of the particle, with a concentration that becomes progressively depleted towards the center of the particle as $k_{\mathrm{c}}$ increases. Thus, the particle growth is volume-reaction controlled when the concentration profile is uniform and tends to be surface-reaction controlled at the other extreme.

Since the timescale for diffusion varies as $R_{\mathrm{p}}^{2}$, the diffusion limitation to reaction also depends strongly on particle size. As shown in Fig. 4, the relative effects of particle size, bulk diffusivity, and reaction rate on the shape of the steadystate concentration profiles are concisely captured in terms of the dimensionless parameter $q$, which is a function of $R_{\mathrm{p}}$, $k_{\mathrm{c}}$, and $D_{\mathrm{b}}$ (Eq. 3). At low values of $q(<0.5)$, the steadystate concentration profile is nearly uniform, but becomes increasingly nonuniform for $q$ values on the order of unity and greater.

While the temporal evolution of the radial concentration profile is highly informative, the timescale to reach steady state, as well as the shape of the steady-state profile, can be conveniently quantified in terms of the average particle-phase concentration $\bar{A}(t)$. We integrate the concentration profile given by Eq. (3) over the volume of the particle to obtain

$$
\frac{\bar{A}_{i}(t)}{A_{i}^{\mathrm{s}}}=\frac{\int_{0}^{R_{\mathrm{p}}} 4 \pi r^{2} \frac{A_{i}(r, t)}{A_{i}^{s}} \mathrm{~d} r}{\frac{4}{3} \pi R_{\mathrm{p}}^{3}}=Q_{i}-U_{i}(t),
$$

where

$$
\begin{aligned}
& Q_{i}=3\left(\frac{q_{i} \operatorname{coth} q_{i}-1}{q_{i}^{2}}\right), \\
& U_{i}(t)=\frac{6}{\pi^{2}} \sum_{n=1}^{\infty} \frac{\exp \left\{-\left(k_{\mathrm{c}, i}+\frac{n^{2} \pi^{2} D_{\mathrm{b}, i}}{R_{\mathrm{p}}^{2}}\right) t\right\}}{\left(q_{i} / \pi\right)^{2}+n^{2}} .
\end{aligned}
$$

Here, $Q_{i}$ is the ratio of the average particle-phase concentration to the surface concentration at steady state, while $U_{i}(t)$ is the transient term, the value of which is always equal to $Q_{i}$ at $t=0$ and decreases exponentially to zero as $t \rightarrow \infty$. As noted earlier, the surface concentration $A_{i}^{\mathrm{s}}$ is assumed to be constant in the analytical solution of Eq. (1). However, since $A_{i}^{\mathrm{s}}$ can gradually change over time due to changes in the gasphase concentration and particle composition, it is more appropriate to refer to the steady state as quasi-steady state. The timescale to reach a quasi-steady state $\left(\tau_{\mathrm{QSS}}\right)$ within the particle can then be defined as the e-folding time for the exponential decay of the unsteady-state term $U_{i}$ relative to the 

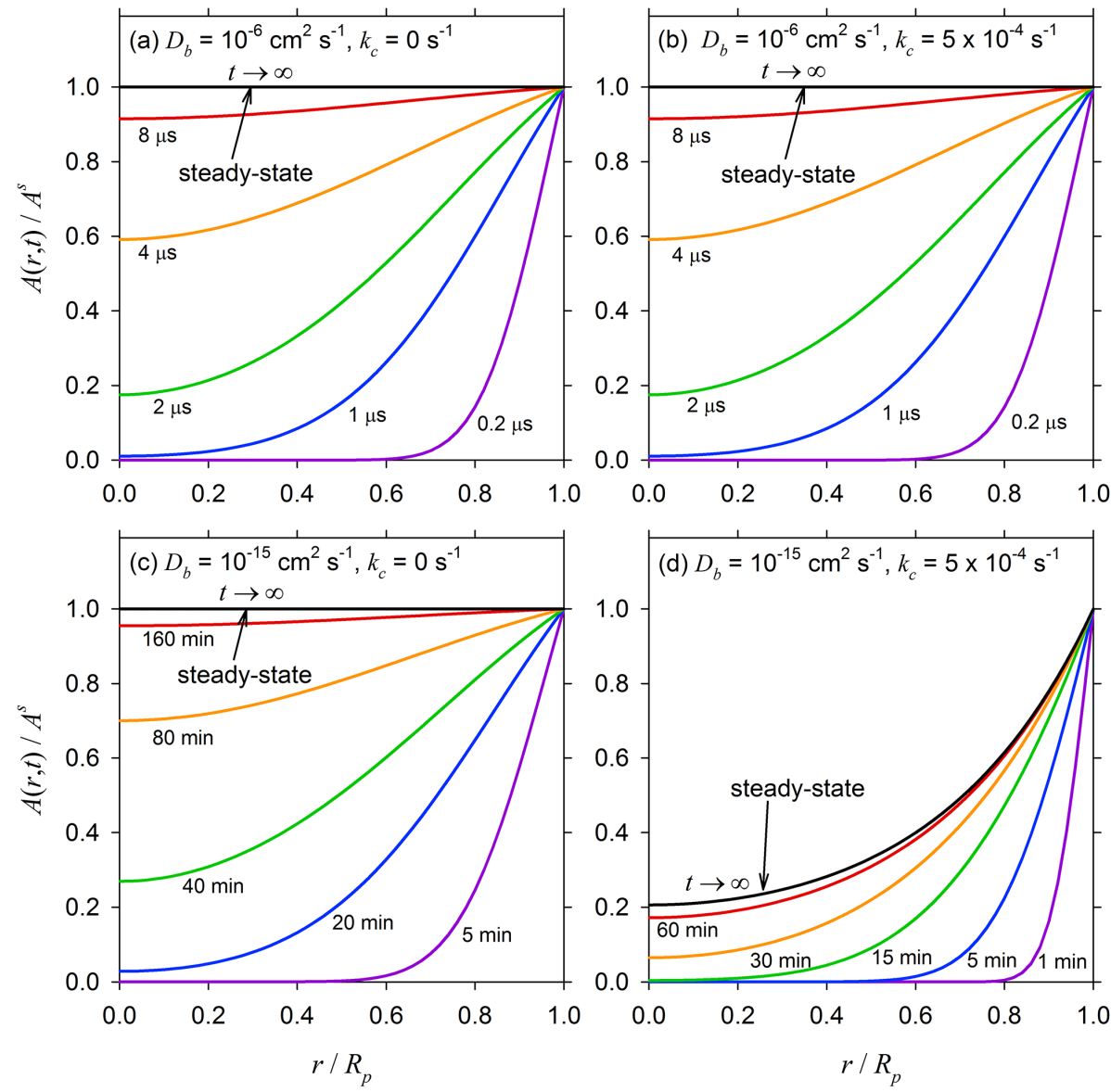

Figure 2. Normalized transient concentration $\left(A(r, t) / A^{\mathrm{S}}\right)$ profiles as a function of normalized radius $\left(r / R_{\mathrm{p}}\right)$ for a particle of diameter $R_{\mathrm{p}}=0.05 \mu \mathrm{m}$ for different values of bulk-phase diffusivity and first-order reaction rate constants: (a) $D_{\mathrm{b}}=10^{-6} \mathrm{~cm}^{2} \mathrm{~s}^{-1}, k_{\mathrm{c}}=0 \mathrm{~s}^{-1} ;(\mathbf{b})$ $D_{\mathrm{b}}=10^{-6} \mathrm{~cm}^{2} \mathrm{~s}^{-1}, k_{\mathrm{c}}=5 \times 10^{-4} \mathrm{~s}^{-1}$; (c) $D_{\mathrm{b}}=10^{-15} \mathrm{~cm}^{2} \mathrm{~s}^{-1}, k_{\mathrm{c}}=0 \mathrm{~s}^{-1}$; and (d) $D_{\mathrm{b}}=10^{-15} \mathrm{~cm}^{2} \mathrm{~s}^{-1}, k_{\mathrm{c}}=5 \times 10^{-4} \mathrm{~s}^{-1}$.

quasi-steady-state term $Q_{i}$. Thus, setting $U_{i}\left(\tau_{\mathrm{QSS}}\right)=Q_{i} / e$, we get

$$
\begin{aligned}
& \sum_{n=1}^{\infty} \frac{\exp \left\{-\left(k_{\mathrm{c}, i}+\frac{n^{2} \pi^{2} D_{\mathrm{b}, i}}{R_{\mathrm{p}}^{2}}\right) \tau_{\mathrm{QSS}}\right\}}{\left(q_{i} / \pi\right)^{2}+n^{2}} \\
& =\frac{1}{e} \times \frac{\pi^{2}}{2}\left(\frac{q_{i} \operatorname{coth} q_{i}-1}{q_{i}^{2}}\right) .
\end{aligned}
$$

For a given set of values for $D_{\mathrm{p}}, D_{\mathrm{b}}$, and $k_{\mathrm{c}}$, Eq. (10) can be numerically solved for $\tau_{\mathrm{QSS}}$ with the bisection method.

We first examine the dependence of $\tau_{\mathrm{QSS}}$ and $Q$ on $D_{\mathrm{b}}$ and $k_{\mathrm{c}}$ for a particle of $D_{\mathrm{p}}=0.1 \mu \mathrm{m}$ (Fig. 5). The values of $D_{\mathrm{b}}$ are varied over 14 orders of magnitude from $10^{-19}$ (almost solid) to $10^{-5} \mathrm{~cm}^{2} \mathrm{~s}^{-1}$ (liquid water) to cover the full range of semisolid and liquid organic particles; and $k_{\mathrm{c}}$ values are varied over 6 orders of magnitude from of $10^{-6}$ (very slow reaction) to $1 \mathrm{~s}^{-1}$ (practically instantaneous reaction). As seen in Fig. 5a, the contours of $\tau_{\mathrm{QSS}}$ range from $1 \mu$ s for liquid particles to 1 day for highly viscous semisolid particles. For the semisolid particles, there are two regions in the semisolid zone as depicted by the gray dotted line. In the region above the dotted line, $\tau_{\mathrm{QSS}}$ is sensitive only to the value of $k_{\mathrm{c}}$ and decreases rapidly with increase in $k_{\mathrm{c}}$. For instance, at $D_{\mathrm{b}}=10^{-19} \mathrm{~cm}^{2} \mathrm{~s}^{-1}, \tau_{\mathrm{SS}} \approx 1$ day for $k_{\mathrm{c}}=5 \times 10^{-6} \mathrm{~s}^{-1}$ but decreases to $<1 \mathrm{~min}$ for $k_{\mathrm{c}}=10^{-2} \mathrm{~s}^{-1}$. In the region below the dotted line, $\tau_{\mathrm{QSS}}$ is sensitive only to the value of $D_{\mathrm{b}}$ for both semisolid and liquid particles. For example, at $D_{\mathrm{b}} \approx 10^{-14} \mathrm{~cm}^{2} \mathrm{~s}^{-1}, \tau_{\mathrm{QSS}}$ remains constant at $\sim 1 \mathrm{~min}$ for $k_{\mathrm{c}}$ values from $10^{-6}$ up to about $10^{-2} \mathrm{~s}^{-1}$ (i.e., up to the dotted line) and only then becomes sensitive to reaction at higher values of $k_{\mathrm{c}}$. $\tau_{\mathrm{QSS}}$ is sensitive to both $k_{\mathrm{c}}$ and $D_{\mathrm{b}}$ only in the relatively narrow envelope along the dotted line itself. As seen in Fig. 5b, the values of $Q$ are $<0.001$ for highly viscous semisolid particles and high $k_{\mathrm{c}}$ values, while they approach unity as $D_{\mathrm{b}}$ increases and $k_{\mathrm{c}}$ decreases. Note that the dotted line in Fig. 5a roughly corresponds to the contour for $Q=0.6$ in Fig. 5 b.

Next, we examine the dependence of $\tau_{\mathrm{QSS}}$ and $Q$ on particle size. Figure 6 shows $\tau_{\mathrm{QSS}}$ vs. $D_{\mathrm{p}}$ for $D_{\mathrm{b}}$ values ranging from $10^{-18}$ to $10^{-10} \mathrm{~cm}^{2} \mathrm{~s}^{1}$ for (a) $k_{\mathrm{c}}=0 \mathrm{~s}^{-1}$, (b) $k_{\mathrm{c}}=10^{-3} \mathrm{~s}^{-1}$, (c) $k_{\mathrm{c}}=0.01 \mathrm{~s}^{-1}$, and (d) $k_{\mathrm{c}}=0.1 \mathrm{~s}^{-1}$. As 

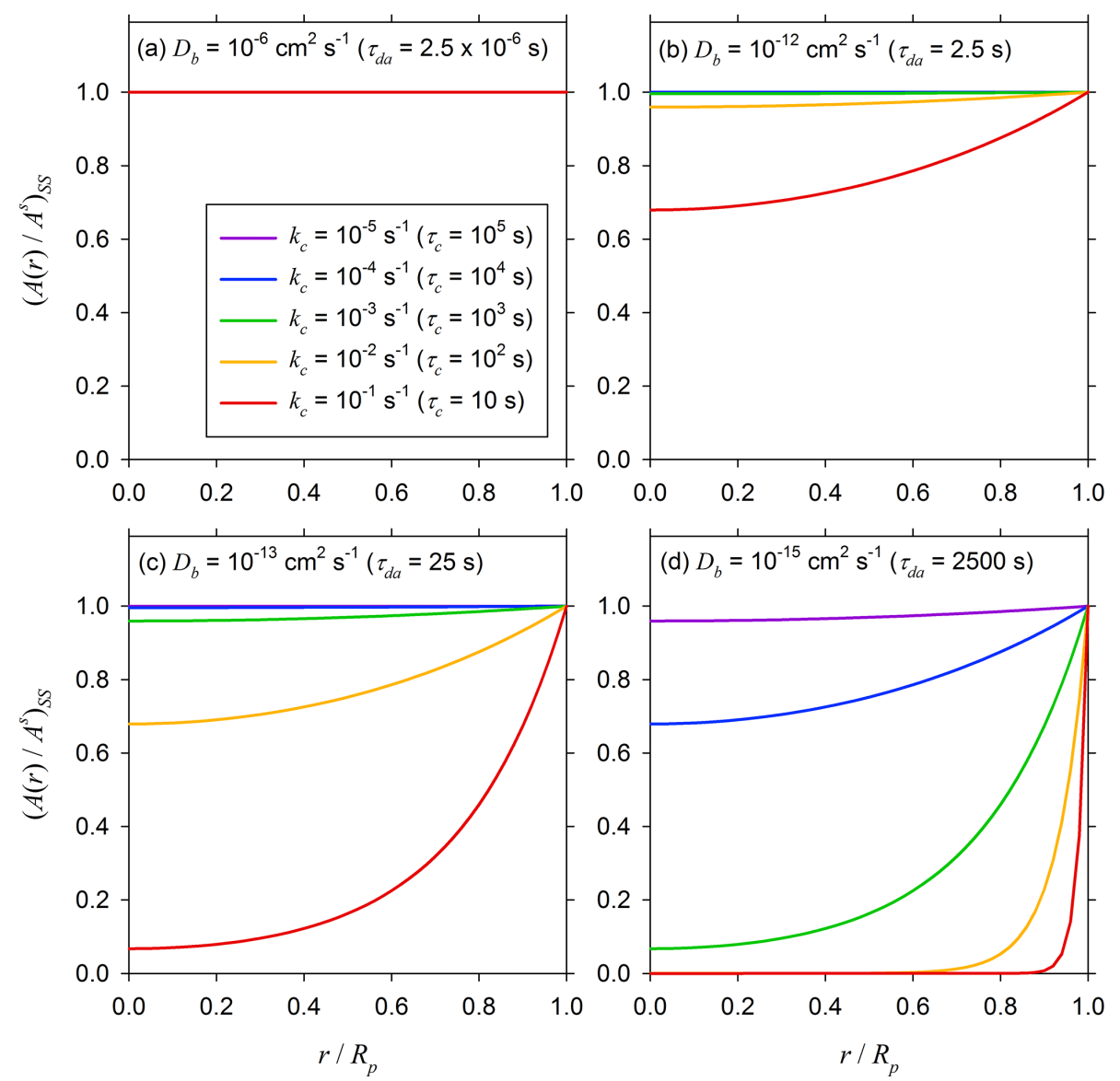

Figure 3. Normalized steady-state concentration $\left(A(r) / A^{\mathrm{s}}\right)_{\mathrm{SS}}$ profiles as a function of $r / R_{\mathrm{p}}$ for a particle of diameter $R_{\mathrm{p}}=0.05 \mu \mathrm{m}$ and a range of $k_{\mathrm{c}}$ values for (a) $D_{\mathrm{b}}=10^{-6} \mathrm{~cm}^{2} \mathrm{~s}^{-1}$, (b) $D_{\mathrm{b}}=10^{-12} \mathrm{~cm}^{2} \mathrm{~s}^{-1}$, (c) $D_{\mathrm{b}}=10^{-13} \mathrm{~cm}^{2} \mathrm{~s}^{-1}$, and (d) $D_{\mathrm{b}}=10^{-15} \mathrm{~cm}^{2} \mathrm{~s}^{-1}$.

seen in Fig. 6a, for any given $D_{\mathrm{b}}, \tau_{\mathrm{QSS}}$ increases by five orders of magnitude as $D_{\mathrm{p}}$ increases from 0.003 to $1 \mu \mathrm{m}$. At the upper end, particles with $D_{\mathrm{b}}<10^{-18} \mathrm{~cm}^{2} \mathrm{~s}^{-1}$ have a $\tau_{\mathrm{QSS}}$ of about $10 \mathrm{~min}$ at $D_{\mathrm{p}}=0.003 \mu \mathrm{m}$ and increase to more than $10^{4} \mathrm{~min}$ at $D_{\mathrm{p}}=0.1 \mu \mathrm{m}$. In contrast, particles with $D_{\mathrm{b}}>10^{-12} \mathrm{~cm}^{2} \mathrm{~s}^{-1}$ have $\tau_{\mathrm{QSS}}$ below 1 min (indicated by the dotted gray line) for sizes up to $0.7 \mu \mathrm{m}$. From a practical standpoint, since most ambient SOA particles are smaller than $\sim 0.7 \mu \mathrm{m}$, concentration profiles of nonreacting solutes inside particles with $D_{\mathrm{b}}>10^{-12} \mathrm{~cm}^{2} \mathrm{~s}^{-1}$ may be assumed to be at steady-state. However, significant diffusion limitation can exist for nonreacting solutes in particles with $D_{\mathrm{b}}$ $<10^{-12} \mathrm{~cm}^{2} \mathrm{~s}^{-1}$ depending on their size. In stark contrast, for reacting solutes, $\tau_{\mathrm{QSS}}$ asymptotically approaches a common maximum value for all values of $D_{\mathrm{b}}$ as the particle size increases as shown in Fig. 6b, c, and d. This maximum value of $\tau_{\mathrm{QSS}}$ is about 7, 0.7 , and $0.07 \mathrm{~min}$ for $k_{\mathrm{c}}=10^{-3}$, $10^{-2}$, and $0.1 \mathrm{~s}^{-1}$, respectively. The typical timescale for changes in the bulk gas-phase concentrations due to transport and chemical reaction is on the order $10 \mathrm{~min}$ or more. Thus, from a practical standpoint, the particle-phase concentration profiles of solutes reacting with $k_{\mathrm{c}}>10^{-2} \mathrm{~s}^{-1}$ (for which $\tau_{\mathrm{QSS}} \leq 0.7 \mathrm{~min}$ ) may be assumed to be at quasi-steady state in particles of any size and any $D_{\mathrm{b}}$ value.

Figure 7 illustrates variation of $Q$ with $D_{\mathrm{p}}$ for the four cases shown in Fig. 6. At quasi-steady state, the particlephase concentration profile for nonreacting solutes is always uniform (i.e., $Q=1$ ) even though $\tau_{\mathrm{QSS}}$ can differ significantly depending on the particle size and $D_{\mathrm{b}}$ value (Fig. 7a). For reacting solutes with $k_{\mathrm{c}}$ up to $0.1 \mathrm{~s}^{-1}, Q$ remains nearly equal to unity in particles with $D_{\mathrm{b}}>10^{-10} \mathrm{~cm}^{2} \mathrm{~s}^{-1}$ and $D_{\mathrm{p}}$ up to $1 \mu \mathrm{m}$. For $D_{\mathrm{b}}<10^{-10} \mathrm{~cm}^{2} \mathrm{~s}^{-1}, Q$ decreases as $D_{\mathrm{p}}$ increases for a given $D_{\mathrm{b}}$, while it increases as $D_{\mathrm{b}}$ increases for a given $D_{\mathrm{p}}$.

In general, the above analysis indicates that (a) for a given $D_{\mathrm{p}}$, a more reactive solute will reach quasi-steady state sooner and exhibit a more nonuniform concentration profile than a less reactive one, especially in particles with lower $D_{\mathrm{b}}$ than higher, and (b) for a given set of values for $k_{\mathrm{c}}$ and $D_{\mathrm{b}}$, a solute in smaller particles will reach quasi-steady state sooner and exhibit a more uniform quasi-steady-state concentration profile than in larger particles. 


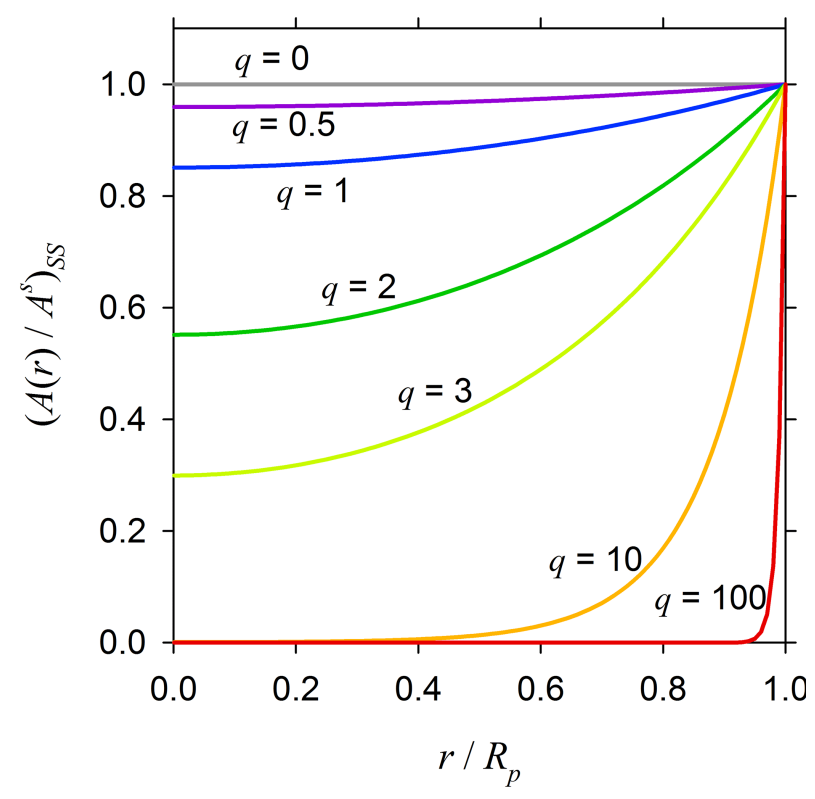

Figure 4. Normalized $\left(A(r) / A^{\mathrm{s}}\right)$ SS profiles as a function of $r / R_{\mathrm{p}}$ for different values of the dimensionless diffuso-reactive parameter $q$.

\section{Kinetic gas-particle partitioning model}

We shall now describe the development of a new framework for modeling kinetic partitioning of SOA based on the insights gained from timescale analysis of the diffusionreaction process within the particle phase. The framework takes into account solute volatility, gas-phase diffusion, interfacial mass accommodation, particle-phase diffusion, and particle-phase reaction. However, instead of numerically resolving the concentration gradient inside the particle (Shiraiwa et al., 2012a), which is computationally expensive and therefore impractical for inclusion in 3-D Eulerian models, we use the analytical expressions of the quasi-steady state and transient behavior of the solute diffusing and reacting within the particle.

\subsection{Model framework}

\subsubsection{Single particle equations}

We begin by relating the average particle-phase concentration of the solute $\bar{A}_{i}\left(\mathrm{~mol} \mathrm{~cm}^{-3}\right.$ (particle)) to its average bulk gas-phase concentration $\bar{C}_{\mathrm{g}, i}\left(\mathrm{~mol} \mathrm{~cm}{ }^{-3}\right.$ (air)) over a single particle. Similar to the timescale for diffusion in the particle phase (Eq. 5), the timescale for the gas-phase concentration gradient outside the particle to reach a quasi-steady state $\left(\tau_{\mathrm{dg}}\right)$ is given by Seinfeld and Pandis (2006):

$\tau_{d g, i}=\frac{R_{\mathrm{p}}^{2}}{\pi^{2} D_{\mathrm{g}, i}}$, where $D_{\mathrm{g}, i}\left(\mathrm{~cm}^{2} \mathrm{~s}^{-1}\right)$ is the gas-phase diffusivity. For a typical $D_{\mathrm{g}, i}$ of $0.05 \mathrm{~cm}^{2} \mathrm{~s}^{-1}$, the value of $\tau_{\mathrm{dg}}$ is on the order $10^{-8} \mathrm{~s}$ or less for submicron-size aerosols, which is much smaller than the typical timescale for changes in the bulk gas-phase concentration in the ambient atmosphere. We can therefore safely assume that the gas-phase concentration profile of the solute around the particle is at quasi-steady state at any instant.

An ordinary differential equation describing the rate of change of $\bar{A}_{i}$ due to mass transfer between gas and a single particle with particle-phase reaction can then be written as

$\frac{d \bar{A}_{i}}{\mathrm{~d} t}=\frac{3}{R_{\mathrm{p}}} k_{\mathrm{g}, i}\left(\bar{C}_{\mathrm{g}, i}-C_{\mathrm{g}, i}^{\mathrm{s}}\right)-k_{\mathrm{c}, i} \bar{A}_{i}$,

where $C_{\mathrm{g}, i}^{\mathrm{s}}\left(\mathrm{mol} \mathrm{cm}^{-3}\right.$ (air)) is the gas-phase concentration of the solute just outside the surface of the particle, and $k_{\mathrm{g}, i}$ $\left(\mathrm{cm} \mathrm{s}^{-1}\right)$ is the gas-side mass-transfer coefficient given as

$k_{\mathrm{g}, i}=\frac{D_{\mathrm{g}, i}}{R_{\mathrm{p}}} f\left(K n_{i}, \alpha_{i}\right)$.

Here $f\left(K n_{i}, \alpha_{i}\right)$ is the transition regime correction factor (Fuchs and Sutugin, 1971) to the Maxwellian flux as a function of the Knudsen number $K n_{i}=\lambda_{i} / R_{\mathrm{p}}$ (where $\lambda_{i}$ is the mean free path) and the so-called mass accommodation coefficient, $\alpha_{i}$, which is defined as the fraction $\left(0 \leq \alpha_{i} \leq 1\right)$ of the incoming molecules that is incorporated into the particle surface:

$f\left(K n_{i}, \alpha_{i}\right)=\frac{0.75 \alpha_{i}\left(1+K n_{i}\right)}{K n_{i}\left(1+K n_{i}\right)+0.283 \alpha_{i} K n_{i}+0.75 \alpha_{i}}$.

While the above correction factor was derived from a numerical solution of the Boltzmann diffusion equation for neutron transfer to a black sphere (i.e., representative of light molecules in a heavy background gas), its applicability for higher-molecular-weight trace gases in air has been experimentally confirmed (Seinfeld and Pandis, 2006, and references therein).

The timescale to achieve interfacial phase equilibrium between $C_{\mathrm{g}, i}^{\mathrm{s}}$ and the particle-phase concentration of $i$ just inside the surface, $A_{i}^{\mathrm{s}}\left(\mathrm{mol} \mathrm{cm}^{-3}\right.$ (particle)), is at least (Seinfeld and Pandis, 2006)

$\tau_{\mathrm{p}, i}=D_{\mathrm{b}, i}\left(\frac{4}{\alpha_{i} \bar{v}_{i}}\right)^{2}$,

where $\bar{v}_{i}$ is the average speed of solute molecules in the gas phase. From kinetic theory of gases $\bar{v}_{i}=\left(8 \Re T / \pi M_{i}\right)^{1 / 2}$ where $\Re$ is the universal gas constant $\left(8.314 \times 10^{7}\right.$ erg $\left.\mathrm{K}^{-1} \mathrm{~mol}^{-1}\right), T(K)$ is temperature, and $M_{i}$ is the molecular weight of the solute. For representative values of $D_{\mathrm{b}, i} \leq$ $10^{-5} \mathrm{~cm}^{2} \mathrm{~s}^{-1}, M_{i}=100 \mathrm{~g} \mathrm{~mol}^{-1}, T=298 \mathrm{~K}$, and $\alpha_{i}$ ranging from 0.1 to 0.001 , the value of $\tau_{\mathrm{p}, i}$ is on the order $10^{-6} \mathrm{~s}$ or 
(a) $\tau_{\text {OSS }}$

(b) $Q$
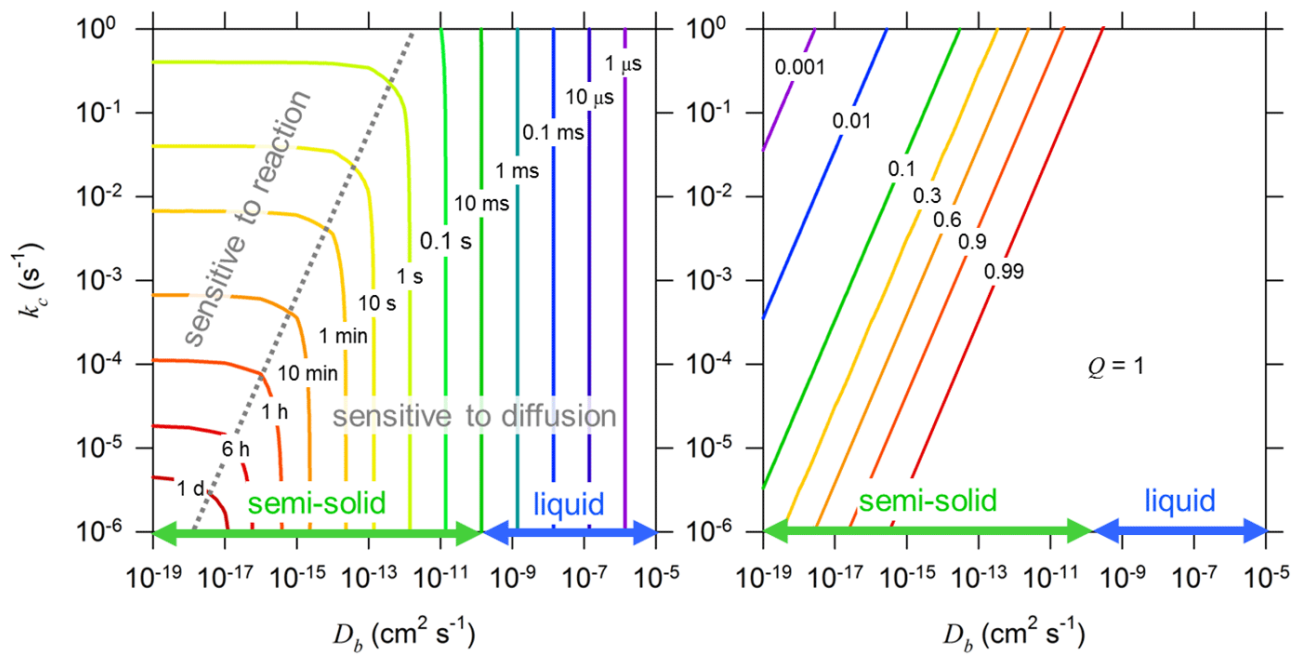

Figure 5. (a) Contour plots of: (a) particle-phase quasi-steady-state timescale $\left(\tau_{\mathrm{QSS}}\right)$, and (b) quasi-steady-state parameter $Q=\left(\bar{A} / A^{\mathrm{s}}\right) \mathrm{QSS}$ as functions of first-order rate constant $\left(k_{\mathrm{c}}\right)$ and bulk diffusion coefficient $\left(D_{\mathrm{b}}\right)$ for a species diffusing and reacting within semisolid and liquid particles of diameter $D_{\mathrm{p}}=0.1 \mu \mathrm{m}$.

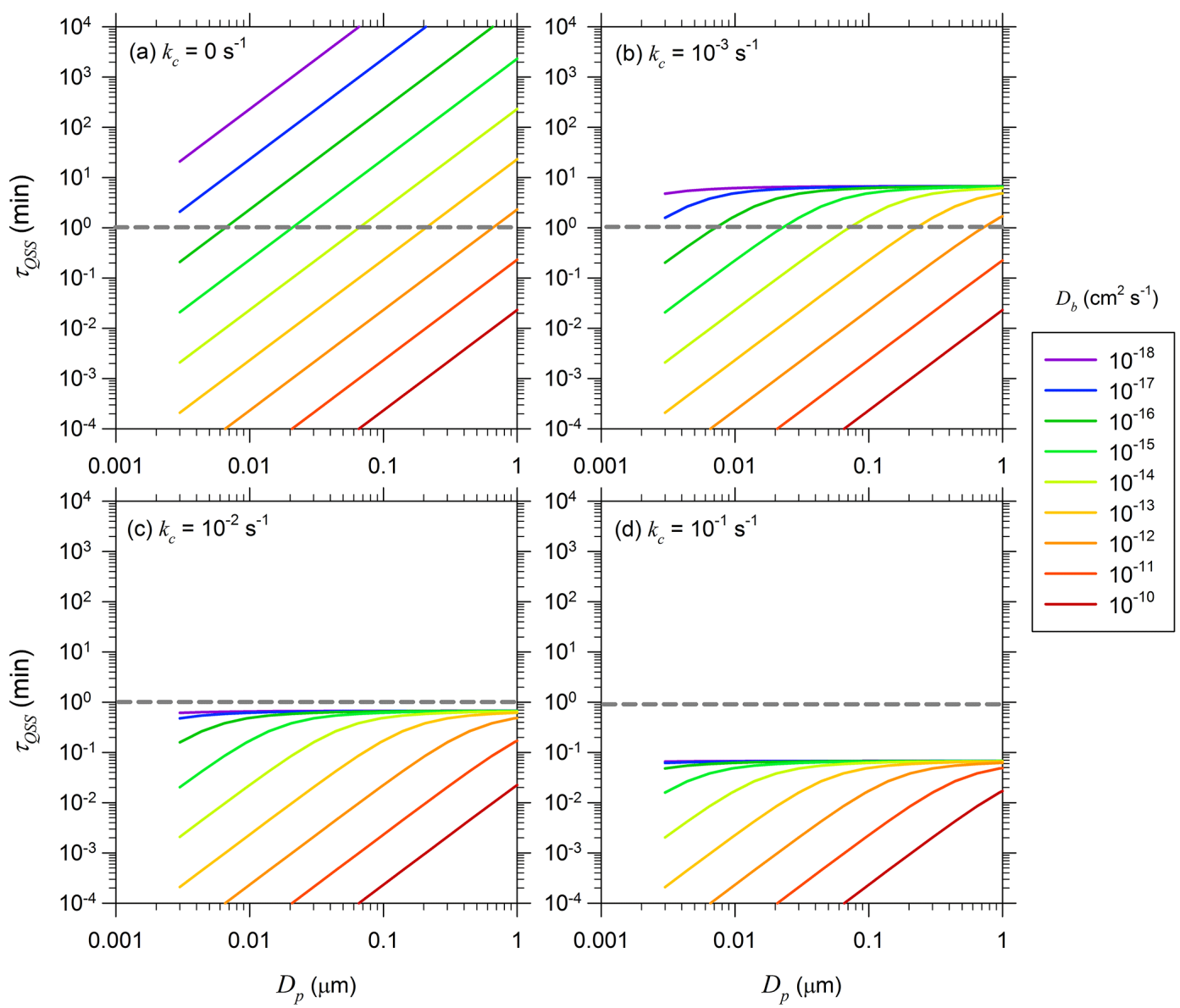

Figure 6. Dependence of $\tau_{\mathrm{QSS}}$ on particle diameter $D_{\mathrm{p}}$ for $D_{\mathrm{b}}$ values ranging from $10^{-10}$ to $10^{-18} \mathrm{~cm}^{2} \mathrm{~s}^{-1}:$ (a) $k_{\mathrm{c}}=0 \mathrm{~s}^{-1}$, (b) $k_{\mathrm{c}}=10^{-3} \mathrm{~s}^{-1}$, (c) $k_{\mathrm{c}}=10^{-2} \mathrm{~s}^{-1}$, and (d) $k_{\mathrm{c}}=10^{-1} \mathrm{~s}^{-1}$. 

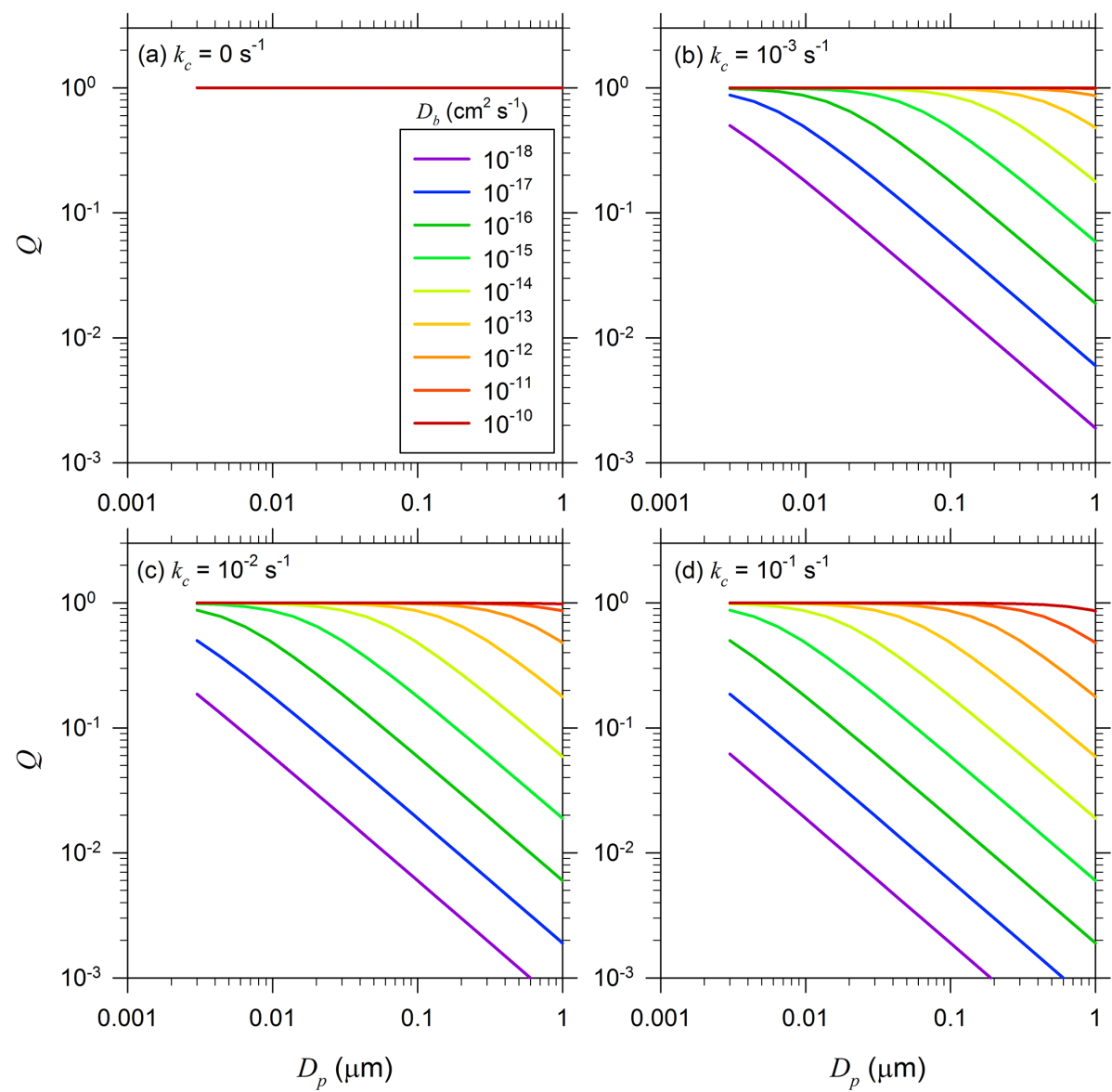

Figure 7. Dependence of $Q$ on particle diameter $D_{\mathrm{p}}$ for $D_{\mathrm{b}}$ values ranging from $10^{-10}$ to $10^{-18} \mathrm{~cm}^{2} \mathrm{~s}^{-1}$ : (a) $k_{\mathrm{c}}=0 \mathrm{~s}^{-1}$, (b) $k_{\mathrm{c}}=10^{-3} \mathrm{~s}^{-1}$, (c) $k_{\mathrm{c}}=10^{-2} \mathrm{~s}^{-1}$, and (d) $k_{\mathrm{c}}=10^{-1} \mathrm{~s}^{-1}$.

less, which means it can be safely assumed that the interfacial phase equilibrium is achieved virtually instantaneously. We thus relate $C_{\mathrm{g}, i}^{\mathrm{s}}$ and $A_{i}^{\mathrm{s}}$ according to Raoult's law as

$C_{\mathrm{g}, i}^{\mathrm{s}}=\frac{A_{i}^{\mathrm{s}}}{\sum_{j} A_{j}^{\mathrm{s}}} C_{\mathrm{g}, i}^{*}$,

where $C_{\mathrm{g}, i}^{*}$ is the effective saturation vapor concentration $\left(\mathrm{mol} \mathrm{cm}{ }^{-3}\right.$ (air)), and $\sum_{j} A_{j}^{\mathrm{s}}$ is the total particle-phase concentration of all the organic species at the surface. However, since the surface concentrations of all the species are not always known, we use the total average particle-phase concentration $\sum_{j} \bar{A}_{j}$ as an approximation for $\sum_{j} A_{j}^{\mathrm{s}}$. Thus Eq. (12) is rewritten in terms of $A_{i}^{\mathrm{s}}$ as

$\frac{d \bar{A}_{i}}{\mathrm{~d} t}=\frac{3}{R_{\mathrm{p}}} k_{\mathrm{g}, i}\left(\bar{C}_{\mathrm{g}, i}-\frac{A_{i}^{\mathrm{s}}}{\sum_{j} \bar{A}_{j}} C_{\mathrm{g}, i}^{*}\right)-k_{\mathrm{c}, i} \bar{A}_{i}$.

$A_{i}^{\mathrm{s}}$ can be assumed to be equal to $\bar{A}_{i}$ in liquid particles for a nonreactive or slowly reacting solute that quickly attains a uniform concentration profile (as was previously shown in Fig. 2a, b). But, as discussed in the previous section, this equality may not hold for reactive and nonreactive solutes in semisolid particles. In such cases, Eq. (7) can be used to express $A_{i}^{\mathrm{s}}$ in terms of $\bar{A}_{i}$ as long as $A_{i}^{\mathrm{s}}$ does not change with time, because the analytical solution to Eq. (1) assumes a constant $A_{i}^{\mathrm{s}}$ according to the boundary condition (Eq. 2b). In practice, however, Eq. (7) can be used if the timescale for changes in $A_{i}^{\mathrm{s}}$ are much greater than the timescale for the solute to relax to its quasi-steady-state profile inside the particle. With this caveat, we get

$\frac{d \bar{A}_{i}}{\mathrm{~d} t}=\frac{3}{R_{\mathrm{p}}} k_{\mathrm{g}, i}\left\{\bar{C}_{\mathrm{g}, i}-\frac{\bar{A}_{i}}{\sum_{j} \bar{A}_{j}} \frac{C_{\mathrm{g}, i}^{*}}{\left(Q_{i}-U_{i}(t)\right)}\right\}-k_{\mathrm{c}, i} \bar{A}_{i}$.

Note that Eq. (18) describes kinetic mass transfer of species $i$ between bulk gas-phase and a single particle, with chemical reaction within the particle phase, and includes mass-transfer limitations due to gas-phase diffusion, interfacial mass accommodation, and particle-phase diffusion. Previously, the mass accommodation coefficient $(\alpha)$ has been often used as a tunable parameter to fit the observed kinetic limitation to 
mass-transfer during SOA partitioning (Bowman et al.,1997; Saathoff et al., 2009; Parikh et al., 2011). However, $\alpha$ does not correctly capture the mass-transfer limitations due to diffusion and chemical reaction occurring within the bulk of the particle. In the present framework, the interfacial and bulk particle-phase limitations to mass transfer are represented separately, with the appropriate dependence for the latter on particle size.

In Eq. (18), the term $U_{i}(t)$ is to be evaluated at the "time since start". Equation (18) can therefore only be used in a Lagrangian box model framework for a "closed system" where we can specify an initial concentration of the solute vapor (at time $t=0$ ), which then partitions to the particle phase as a function of time. The solute vapor in the closed system is not subjected to emissions, dilution, and loss due to gasphase oxidation. In the case of no particle-phase reaction, the solute vapor will eventually reach equilibrium with the particles. In the presence of particle-phase reaction, the solute vapor concentration will eventually decay to zero. This is in stark contrast with the "general system" such as the ambient atmosphere and 3-D atmospheric chemistry transport models where the solute vapor at a given location may continuously change due to emissions, dilution, and gas-phase chemistry in addition to gas-particle partitioning. As a result, it is not possible to evaluate $U_{i}(t)$ in the general system, because we cannot keep track of the "time since start" in the same sense as used in the transient analytical solution to Eq. (1). Therefore, based on the value of $k_{\mathrm{c}}$ and the associated timescale for the particle-phase concentration profile to reach quasi-steady state $\left(\tau_{\mathrm{QSS}}\right)$, the following two approximations to Eq. (18) are made for it to be applicable to the general system.

\section{Approximation 1: for fast reactions $\left(k_{\mathrm{c}, i} \geq 0.01 \mathrm{~s}^{-1}\right)$}

As discussed in the previous section (Fig. $6 \mathrm{c}$ ), $\tau_{\mathrm{QSS}}$ for a solute reacting with $k_{\mathrm{c}, i} \geq 0.01 \mathrm{~s}^{-1}$ is less than $1 \mathrm{~min}$ in particles with any $D_{\mathrm{b}}$ and of any size. Compared to the typical time step values of $5 \mathrm{~min}$ or greater in 3-D Eulerian models, the particle-phase concentration profile for solutes with $\tau_{\mathrm{QSS}} \leq 1 \mathrm{~min}$ may be assumed to be at quasi-steady state, and the term $U_{i}(t)$ can be safely neglected in Eq. (17) to yield

$\frac{d \bar{A}_{i}}{\mathrm{~d} t}=\frac{3}{R_{\mathrm{p}}} k_{\mathrm{g}, i}\left\{\bar{C}_{\mathrm{g}, i}-\frac{\bar{A}_{i}}{\sum_{j} \bar{A}_{j}} \frac{C_{\mathrm{g}, i}^{*}}{Q_{i}}\right\}-k_{\mathrm{c}, i} \bar{A}_{i}$

for $k_{\mathrm{c}, i} \geq 0.01 \mathrm{~s}^{-1}$.

A similar equation was derived by Shi and Seinfeld (1991) for reactive mass transport of $\mathrm{SO}_{2}$ (with Henry's law for absorption) in cloud droplets assuming quasi-steady state within the droplet phase. Now, as $k_{\mathrm{c}} \rightarrow 0, Q \rightarrow 1$, and mass transfer is governed entirely by gas-phase diffusion and interfacial mass accommodation in Eq. (19). As a result, Eq. (19) tends to lose its ability to capture the resistance to mass transfer due to slow diffusion in the particle phase as $k_{\mathrm{c}} \rightarrow 0$.
Therefore, an alternate treatment for mass transfer is needed for slow reactions.

\section{Approximation 2: for slow reactions $\left(k_{\mathrm{c}, i}<0.01 \mathrm{~s}^{-1}\right)$}

For $k_{\mathrm{c}, i}<0.01 \mathrm{~s}^{-1}$ (or $\tau_{\mathrm{QSS}}>1 \mathrm{~min}$ ), we use the classical two-film theory of mass transfer between the gas and particle phases. The two-film theory was originally introduced by Lewis and Whitman (1924) and has been widely used to model mass transfer in two phase systems, with and without chemical reactions (Astarita, 1967; Doraiswamy and Sharma, 1984; Bird et al., 2007). Figure 8 shows the schematic of the two-film model, which assumes that the concentration gradients in the gas and particle phases are confined in the respective hypothetical "films" adjacent to the interface. The gas- and particle-side film thicknesses are denoted by $\delta_{\mathrm{g}}$ and $\delta_{\mathrm{p}}(\mathrm{cm})$, respectively, and the respective mass-transfer coefficients $\left(\mathrm{cm} \mathrm{s}^{-1}\right)$ are defined as $k_{\mathrm{g}}=$ $D_{\mathrm{g}} / \delta_{\mathrm{g}}$ and $k_{\mathrm{p}}=D_{\mathrm{b}} / \delta_{\mathrm{p}}$. The overall gas-side mass-transfer coefficient $K_{\mathrm{g}}\left(\mathrm{cm} \mathrm{s}^{-1}\right)$ is then given by (see Appendix A for the derivation)

$$
\frac{1}{K_{\mathrm{g}, i}}=\frac{1}{k_{\mathrm{g}, i}}+\frac{1}{k_{\mathrm{p}, i}}\left(\frac{C_{\mathrm{g}, i}^{*}}{\sum_{j} \bar{A}_{j}}\right) \text {. }
$$

The ordinary differential equation describing the rate of change of $\bar{A}_{i}$ due to gas-particle mass-transfer and particlephase reaction can then be written in terms of the overall driving force as

$$
\frac{d \bar{A}_{i}}{\mathrm{~d} t}=\frac{3}{R_{\mathrm{p}}} K_{\mathrm{g}, i}\left\{\bar{C}_{\mathrm{g}, i}-\frac{\bar{A}_{i}}{\sum_{j} \bar{A}_{j}} C_{\mathrm{g}, i}^{*}\right\}-k_{\mathrm{c}, i} \bar{A}_{i}
$$

for $k_{\mathrm{c}, i}<0.01 \mathrm{~s}^{-1}$.

A similar equation was derived by Zaveri (1997) for reactive mass transport of $\mathrm{SO}_{2}$ (with Henry's law for absorption) in cloud droplets assuming quasi-steady state within the droplet phase. The advantage of the two-film model formulation is that the diffusion limitations from both the gas and particle sides are represented in the overall mass-transfer coefficient, and can therefore be used to model mass transfer of slowreacting solutes. The gas-side mass-transfer coefficient $\left(k_{\mathrm{g}}\right)$ is already known from Eq. (13) where $\delta_{\mathrm{g}}=R_{\mathrm{p}}$. However, the particle-side film thickness, $\delta_{\mathrm{p}}$, and therefore $k_{\mathrm{p}}$, are not readily known. In a general system, the bulk gas- and particlephase concentrations of a reactive semivolatile solute tend to reach a quasi-steady state when the net source rate of the solute in the gas phase is relatively steady. Since both Eqs. (19) and (21) describe the same process, they should predict identical gas- and particle-phase concentrations at quasi-steadystate. Thus, setting $d \bar{A}_{i} / d t=0$ in both Eqs. (19) and (21) and equating the expressions for $\bar{A}_{i} / \bar{C}_{\mathrm{g}, i}$ resulting from each of them yields the general expressions for $\delta_{\mathrm{p}}$ and $k_{\mathrm{p}}$ in terms of $D_{\mathrm{b}}, k_{\mathrm{c}}$, and $R_{\mathrm{p}}$ (see Appendix B for the derivation):

$\delta_{\mathrm{p}, i}=R_{\mathrm{p}}\left(\frac{1-Q_{i}}{q_{i} \operatorname{coth} q_{i}-1}\right)$, 
$k_{\mathrm{p}, i}=\frac{D_{\mathrm{b}, i}}{R_{\mathrm{p}}}\left(\frac{q_{i} \operatorname{coth} q_{i}-1}{1-Q_{i}}\right)$.

For the limiting case of a nonreactive solute, $k_{\mathrm{c}} \rightarrow 0, q \rightarrow 0$, $Q \rightarrow 1$ and Eq. (23) reduces to

$k_{\mathrm{p}, i}=5 \frac{D_{\mathrm{b}, i}}{R_{\mathrm{p}}}$.

\subsubsection{Polydisperse aerosol equations}

We now extend the closed system box model Eq. (18) for a single particle to a polydisperse aerosol in a sectional framework. For a given size-section $m$, with number concentration $N_{m}\left(\mathrm{~cm}^{-3}(\right.$ air $\left.)\right)$ and particle radius $R_{\mathrm{p}, m}(\mathrm{~cm})$, we define $\bar{C}_{a, i, m}\left(\mathrm{~mol} \mathrm{~cm}^{-3}\right.$ (air)) as the total average concentration of solute $i$ in size-section $m$ :

$\bar{C}_{a, i, m}=\frac{4}{3} \pi R_{\mathrm{p}, m}^{3} N_{m} \bar{A}_{i, m}$.

Multiplying Eq. (18) by $\left(4 \pi R_{\mathrm{p}, m}^{3} N_{m} / 3\right)$ yields:

$\frac{d \bar{C}_{a, i, m}}{\mathrm{~d} t}=4 \pi R_{\mathrm{p}, m}^{2} N_{m} k_{\mathrm{g}, i, m}\left\{\bar{C}_{\mathrm{g}, i}-\bar{C}_{a, i, m} \frac{S_{i, m}}{\left(Q_{i}-U_{i}(t)\right)}\right\}-k_{\mathrm{c}, i} \bar{C}_{a, i, m}$,

where $S_{i, m}$ is the saturation ratio:

$S_{i, m}=\frac{C_{\mathrm{g}, i}^{*}}{\sum_{j} \bar{C}_{a, j, m}}$.

The corresponding equation governing the gas-phase concentration of solute $i$ is

$\frac{d \bar{C}_{\mathrm{g}, i}}{\mathrm{~d} t}=-\sum_{m}\left[4 \pi R_{\mathrm{p}, m}^{2} N_{m} k_{\mathrm{g}, i, m}\left\{\bar{C}_{\mathrm{g}, i}-\bar{C}_{a, i, m} \frac{S_{i, m}}{\left(Q_{i}-U_{i}(t)\right)}\right\}\right]$.

Similarly, the particle-phase and gas-phase equations for polydisperse aerosols in the general system are as follows.

Approximation 1: for $k_{\mathrm{c}, i} \geq 0.01 \mathrm{~s}^{-1}$

$\frac{d \bar{C}_{a, i, m}}{\mathrm{~d} t}=4 \pi R_{\mathrm{p}, m}^{2} N_{m} k_{\mathrm{g}, i, m}\left(\bar{C}_{\mathrm{g}, i}-\bar{C}_{a, i, m} \frac{S_{i, m}}{Q_{i}}\right)-k_{\mathrm{c}, i} \bar{C}_{a, i, m}$,

$\frac{d \bar{C}_{\mathrm{g}, i}}{\mathrm{~d} t}=-\sum_{m}\left[4 \pi R_{\mathrm{p}, m}^{2} N_{m} k_{\mathrm{g}, i, m}\left(\bar{C}_{\mathrm{g}, i}-\bar{C}_{a, i, m} \frac{S_{i, m}}{Q_{i}}\right)\right]$.

Approximation 2: for $k_{\mathrm{c}, i}<0.01 \mathrm{~s}^{-1}$

$\frac{\mathrm{d} \bar{C}_{a, i, m}}{\mathrm{~d} t}=4 \pi R_{\mathrm{p}, m}^{2} N_{m} K_{\mathrm{g}, i, m}\left(\bar{C}_{\mathrm{g}, i}-\bar{C}_{a, i, m} S_{i, m}\right)-k_{\mathrm{c}, i} \bar{C}_{a, i, m}$,

$\frac{\mathrm{d} \bar{C}_{\mathrm{g}, i}}{\mathrm{~d} t}=-\sum_{m}\left[4 \pi R_{\mathrm{p}, m}^{2} N_{m} K_{\mathrm{g}, i, m}\left(\bar{C}_{\mathrm{g}, i}-\bar{C}_{a, i, m} S_{i, m}\right)\right]$.

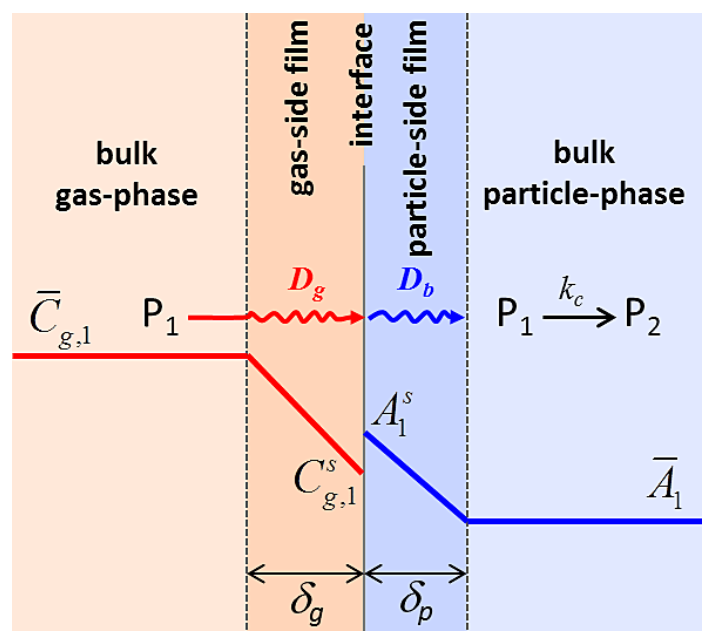

Figure 8. Schematic of the two-film theory.

The proposed framework, described by Eqs. (29) through (32), is relatively simple and amenable for use in regional and global aerosol models, although it presently awaits specification of the actual particle-phase chemical reactions that are important for SOA formation.

We have implemented both the closed system and general system frameworks in the computationally efficient, multicomponent aerosol box-model MOSAIC and adapted the existing semiimplicit Euler method solver to numerically integrate the set of coupled ordinary differential equations for any number of solutes $i$ over any number of size bins $m$ (Zaveri et al., 2008). Sectional growth in MOSAIC is calculated using the two-moment approach of Simmel and Wurzler (2006). The closed system framework is to be used in the box-model version only while the general system framework can be used in both box and 3-D Eulerian models. The complete solution to these equations may be labeled as "seminumerical" because the particle-phase diffusion-reaction process is represented analytically while the set of ordinary differential equations themselves are integrated numerically.

MOSAIC already performs kinetic partitioning of inorganic gases $\left(\mathrm{H}_{2} \mathrm{SO}_{4}, \mathrm{HNO}_{3}, \mathrm{HCl}\right.$, and $\left.\mathrm{NH}_{3}\right)$ to sizedistributed particles and predicts liquid water associated with inorganic species as a function of relative humidity. While the focus of the present work is on kinetic partitioning of organic gases to particulate organic phase, the new framework can be readily adapted to kinetically partition water soluble organic gases into the particulate aqueous phase if that is the only liquid phase in the particle. However, additional research is needed to extend the present framework to mixed inorganic-organic particles that experience liquidliquid phase separation (i.e., coexistence of separate aqueous and organic phases; You et al., 2012). 

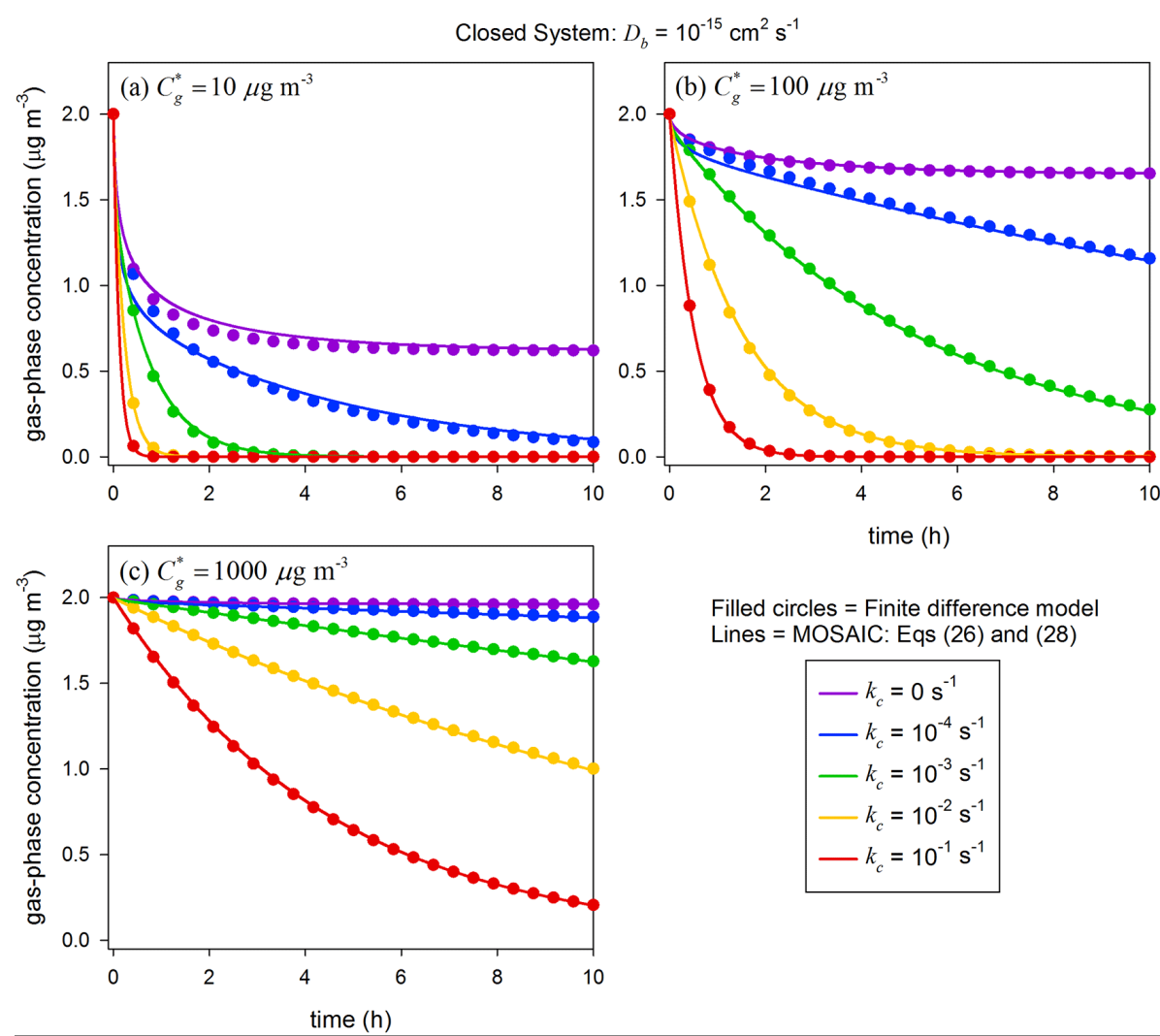

Filled circles $=$ Finite difference model Lines $=$ MOSAIC: Eqs (26) and (28)

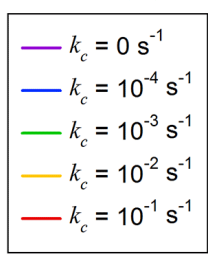

Figure 9. Comparison of MOSAIC (lines) and finite-difference model (filled circles) solutions for gas-phase concentration decay in a closed system due to kinetic gas-particle partitioning to particles with initial $D_{\mathrm{p}}=0.2 \mu \mathrm{m}, N=5000 \mathrm{~cm}^{-3}, D_{\mathrm{b}}=10^{-15} \mathrm{~cm}^{2} \mathrm{~s}-1$ and $k_{\mathrm{c}} \mathrm{ranging}^{-3}$ from 0 to $0.1 \mathrm{~s}^{-1}$ for three solute volatilities: (a) $C_{\mathrm{g}}^{*}=10 \mu \mathrm{g} \mathrm{m}^{-3}$, (b) $C_{\mathrm{g}}^{*}=100 \mu \mathrm{g} \mathrm{m}^{-3}$, and (c) $C_{\mathrm{g}}^{*}=1000 \mu \mathrm{g} \mathrm{m}^{-3}$.

Table 1. Bias and error statistics for MOSAIC predictions for the closed system simulations.

\begin{tabular}{rrrrrrrrrr}
\hline & \multicolumn{3}{c}{$C_{\mathrm{g}}^{*}=10 \mu \mathrm{g} \mathrm{m}^{-3}$} & \multicolumn{3}{c}{$C_{\mathrm{g}}^{*}=100 \mu \mathrm{g} \mathrm{m}^{-3}$} & \multicolumn{3}{c}{$C_{\mathrm{g}}^{*}=1000 \mu \mathrm{g} \mathrm{m}^{-3}$} \\
\cline { 2 - 10 }$k_{\mathrm{c}}$ & MNB & MNGE & maxNGE & MNB & MNGE & maxNGE & MNB & MNGE & $\operatorname{maxNGE}$ \\
$\left(\mathrm{s}^{-1}\right)$ & $(\%)$ & $(\%)$ & $(\%)$ & $(\%)$ & $(\%)$ & $(\%)$ & $(\%)$ & $(\%)$ & $(\%)$ \\
\hline 0 & 4.5 & 4.5 & 7.7 & 0.3 & 0.3 & 0.4 & 0.03 & 0.03 & 0.1 \\
$10^{-4}$ & 8.5 & 11.3 & 19.4 & -1.7 & 1.7 & 3.1 & -0.3 & 0.3 & 0.4 \\
$10^{-3}$ & 10.0 & 11.3 & 25.7 & -1.3 & 1.3 & 3.2 & -0.1 & 0.1 & 0.2 \\
$10^{-2}$ & -1.3 & 1.3 & 3.4 & 3.4 & 3.4 & 4.2 & -0.3 & 0.3 & 1.0 \\
$10^{-1}$ & -4.3 & 4.3 & 10.7 & -2.2 & 2.6 & 7.7 & 0.5 & 0.7 & 1.1 \\
\hline
\end{tabular}

\subsection{Model validation}

We shall now validate the new framework in MOSAIC against a "fully numerical" finite-difference solution to Eq. (1) with a flux-type boundary condition that includes mass transfer of the solute between the gas phase and the particle surface. The volume of the spherical particle is resolved with multiple layers, and diffusion and reaction of the solute species through these layers are integrated numerically. We used 300 uniformly spaced layers in the present exercise. The finite-difference model is conceptually similar to the KM-
GAP model (Shiraiwa et al., 2012a), but does not include reversible adsorption at the surface and heat transfer processes. The finite-difference solution is used as a benchmark here because it rigorously solves Eq. (1) and does not assume the surface concentration to remain constant with time.

For validation purposes, we consider a monodisperse semisolid aerosol composed of nonvolatile organic species $P_{3}$ (molecular weight $100 \mathrm{~g} \mathrm{~mol}^{-1}$ and density $1 \mathrm{~g} \mathrm{~cm}^{-3}$ ), with initial particle diameter $D_{\mathrm{p}}=0.2 \mu \mathrm{m}$, particle number concentration $N=5000 \mathrm{~cm}^{-3}$, and bulk diffusivity $D_{\mathrm{b}}=10^{-15} \mathrm{~cm}^{2} \mathrm{~s}^{-1}$. For simplicity, the molecular weight 
and density of the condensing solute $\left(P_{1}\right)$ and its reaction product species $\left(P_{2}\right)$ are also assumed to be $100 \mathrm{~g} \mathrm{~mol}^{-1}$ and $1 \mathrm{~g} \mathrm{~cm}^{-3}$, respectively. The three species $\left(P_{1}, P_{2}\right.$, and $\left.P_{3}\right)$ are assumed to form an ideal solution that participates in the absorption of $P_{1}$ according to Raoult's law. Model validation is demonstrated below for both closed and general systems.

\subsubsection{Closed system}

In three separate closed system cases, the initial monodisperse aerosol was exposed to the solute $\left(P_{1}\right)$ gas concentration of $2 \mu \mathrm{g} \mathrm{m}^{-3}$ with volatility $C_{\mathrm{g}}^{*}=10,100$, and $1000 \mu \mathrm{g} \mathrm{m}^{-3}$. Figure 9 compares the solution given by MOSAIC (Eqs. 26, 28) with the finite-difference model solution for gas-phase concentration decay due to kinetic gas-particle partitioning for particle-phase reaction rate constants $k_{\mathrm{c}}$ ranging from 0 to $0.1 \mathrm{~s}^{-1}$. When $k_{\mathrm{c}}=0$, the gas-phase concentration reaches an equilibrium value that depends on the solute volatility, while in other cases it decays to zero at different rates as governed by the particle-phase reaction rate constant and diffusion limitation. MOSAIC is able to reproduce the finite-difference results quite well, although small deviations can be seen during the initial portions of the gas decay for $k_{\mathrm{c}} \leq 10^{-4} \mathrm{~s}^{-1}$ and $C_{\mathrm{g}}^{*}=10$ and $100 \mu \mathrm{g} \mathrm{m}^{-3}$. The following metrics were used to quantify the accuracy of MOSAIC relative to the finite-difference (FD) model:

Mean normalized bias, $\mathrm{MNB}=\overline{\left(C_{\mathrm{g}, 1}^{\mathrm{MOSAIC}}-C_{\mathrm{g}, 1}^{\mathrm{FD}}\right) / C_{\mathrm{g}, 1}^{\mathrm{FD}}}$,

Mean normalized gross error, MNGE $=\overline{\left|C_{\mathrm{g}, 1}^{\mathrm{MOSAIC}}-C_{\mathrm{g}, 1}^{\mathrm{FD}}\right| / C_{\mathrm{g}, 1}^{\mathrm{FD}}}$,

Maximum normalized gross error, maxNGE

$=\max \left(\left|C_{\mathrm{g}, 1}^{\mathrm{MOSAIC}}-C_{\mathrm{g}, 1}^{\mathrm{FD}}\right| / C_{\mathrm{g}, 1}^{\mathrm{FD}}\right)$.

These metrics were calculated using the model outputs at $5 \mathrm{~min}$ intervals for the $10 \mathrm{~h}$-long simulations. However, negligibly small gas-phase concentrations $\left(<0.05 \mu \mathrm{g} \mathrm{m}^{-3}\right)$ towards the latter part of the simulations (where applicable) were excluded in the calculations of the metrics. The results are displayed in Table 1. The MNB and MNGE are comparable in magnitude and range from $\sim 0.1$ to $\sim 10 \%$, with values greater than $\sim 5 \%$ seen only for $C_{\mathrm{g}}^{*}=10 \mu \mathrm{g} \mathrm{m}^{-3}$. The large maxNGE values (>20\%) seen for $C_{\mathrm{g}}^{*}=10 \mu \mathrm{g} \mathrm{m}^{-3}$ occur as the gas-phase concentrations approach zero. Overall, the agreement between the two models is quite good for the closed system.

\subsubsection{General system}

In three separate general system cases, the initial monodisperse aerosol was exposed to solute $P_{1}$ with $C_{\mathrm{g}}^{*}=10,100$, and $1000 \mu \mathrm{g} \mathrm{m}^{-3}$ at a constant gas-phase source rate of $\gamma=0.1 \mu \mathrm{g} \mathrm{m}^{-3} \mathrm{~h}^{-1}$ in each case. The initial gas-phase concentration of $P_{1}$ was zero in each case. Figure 10 compares the evolution of the gas-phase concentration of $P_{1}$ predicted by MOSAIC (Eqs. 29-32) and the finite-difference model. The particle-phase reaction rate constant $k_{\mathrm{c}}$ ranged from 0 to $0.1 \mathrm{~s}^{-1}$. When $k_{\mathrm{c}}=0$, the gas-phase concentration of $P_{1}$ increases almost linearly with time upon reaching quasiequilibrium with the particle phase. For $k_{\mathrm{c}}>0$, the gas-phase concentration of $P_{1}$ remains constant after the initial build up as the source rate is balanced by the loss rate due to particle-phase diffusion and reaction. This quasi-steady-state gas-phase concentration level depends on the combination of $C_{\mathrm{g}}^{*}, D_{\mathrm{b}}$, and $k_{\mathrm{c}}$. For $C_{\mathrm{g}}^{*}=10 \mu \mathrm{g} \mathrm{m}^{-3}$, the time required to establish quasi-steady state between gas and particle phases ranges from less than $1 \mathrm{~h}$ at $k_{\mathrm{c}}=0.1 \mathrm{~s}^{-1}$ to more than $20 \mathrm{~h}$ at $k_{\mathrm{c}}=10^{-4} \mathrm{~s}^{-1}$. The time to reach quasi-equilibrium (for nonreactive solutes) and quasi-steady state (for reactive solutes) increases as the value of $C_{\mathrm{g}}^{*}$ increases. Approximations 1 and 2 in MOSAIC are able to capture both the initial "spin-up" phase, when the gas-phase concentration builds up, as well as the later phase where the concentration remains in quasi-equilibrium or quasi-steady state. Furthermore, for $k_{\mathrm{c}}=10^{-3} \mathrm{~s}^{-1}$, approximation 1 (black dotted line in Fig. 10) yields nearly identical results as approximation 2 for all three $C_{\mathrm{g}}^{*}$ values, indicating that the transition from one to the other does not cause a sudden change in the behavior of the solution. Approximation 1 predicts faster gas uptake than the finite-difference model for slow reactions while approximation 2 predicts slower gas uptake than the finite-difference model for fast reactions (not shown), especially for lowvolatility solutes $\left(C_{\mathrm{g}}^{*}=\sim 10 \mu \mathrm{g} \mathrm{m}^{-3}\right)$. A combination of approximations 1 and 2 is thus needed to cover the full range of possible $k_{\mathrm{c}}$ values.

The normalized gross errors in MOSAIC are relatively large during the spin-up phase where the gas-phase concentrations are very small. In a 3-D Eulerian model application, the spin-up phase occurs at the beginning of the simulation and is usually discarded. Here, we discard the first two hours of spin-up in each simulation to avoid small gas-phase concentrations when calculating the bias and error metrics, shown in Table 2. Both MNB and MNGE are generally less than $\sim 3 \%$. The maxNGE values ranged between 0.3 and $8.5 \%$. The overall performance of MOSAIC for the general system is excellent.

\subsection{Future considerations}

While the general system framework is amenable for eventual use in regional and global climate models, it currently awaits specification of the various gas and particle-phase chemistries important for SOA formation. The following issues must be must be taken into consideration when specifying the various physical and chemical details in the model and evaluating it using laboratory and field observations. 

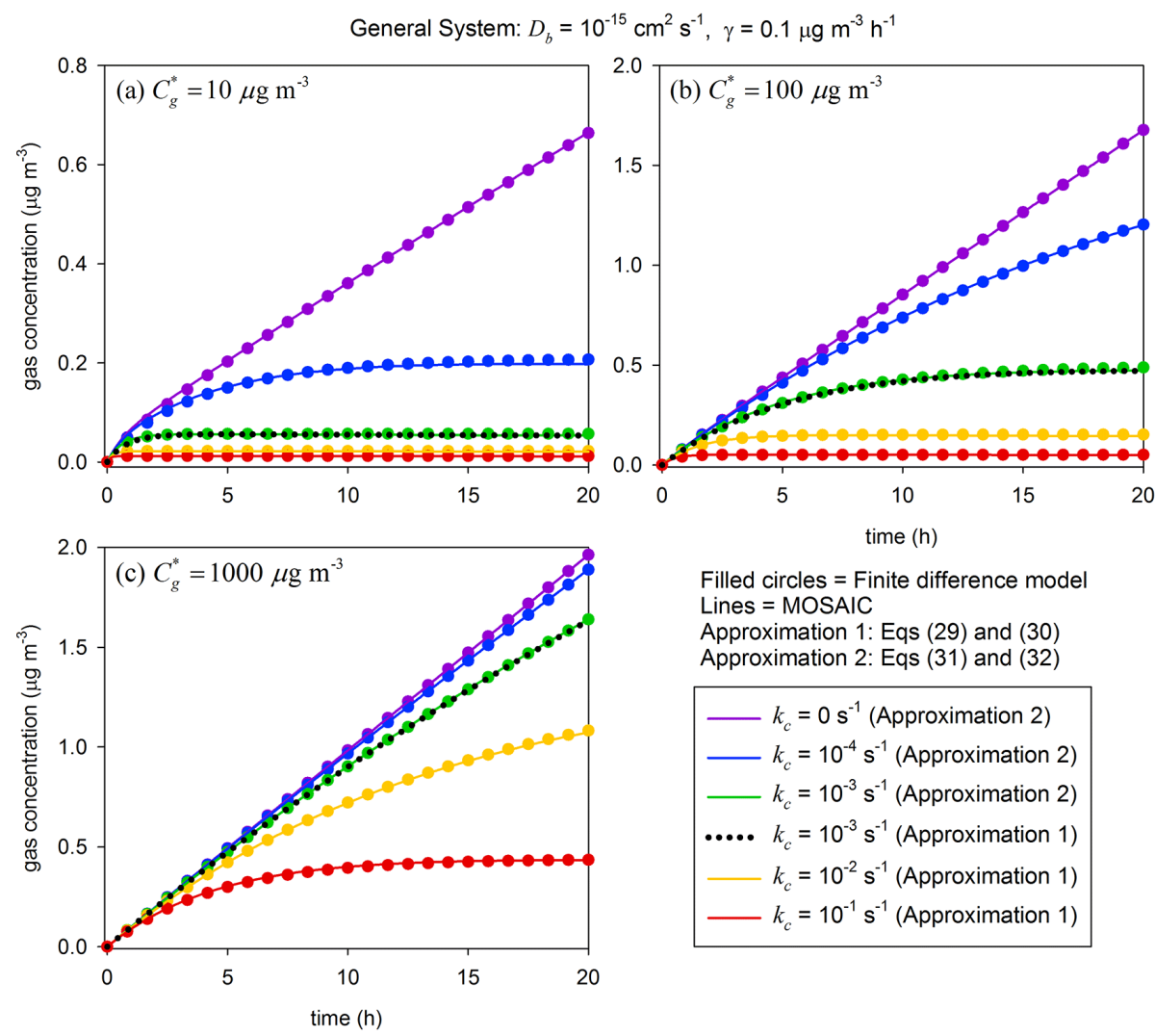

Filled circles $=$ Finite difference model Lines $=$ MOSAIC

Approximation 1: Eqs (29) and (30)

Approximation 2: Eqs (31) and (32)

$\begin{aligned}-k_{c} & =0 \mathrm{~s}^{-1} \text { (Approximation 2) } \\ -k_{c} & =10^{-4} \mathrm{~s}^{-1} \text { (Approximation 2) } \\ -k_{c} & =10^{-3} \mathrm{~s}^{-1} \text { (Approximation 2) } \\ \ldots . . . k_{c} & =10^{-3} \mathrm{~s}^{-1} \text { (Approximation 1) } \\ -k_{c} & =10^{-2} \mathrm{~s}^{-1} \text { (Approximation 1) } \\ -k_{c} & =10^{-1} \mathrm{~s}^{-1} \text { (Approximation 1) }\end{aligned}$

Figure 10. Comparison of MOSAIC (lines) and finite-difference model (filled circles) solutions for gas-phase concentration evolution in a general system due to kinetic gas-particle partitioning to particles with initial $D_{\mathrm{p}}=0.2 \mu \mathrm{m}, N=5000 \mathrm{~cm}^{-3}, D_{\mathrm{b}}=10^{-15} \mathrm{~cm}^{2} \mathrm{~s}^{-1}$, $\gamma=0.1 \mu \mathrm{g} \mathrm{m}^{-3} \mathrm{~h}^{-1}$, and $k_{\mathrm{c}}$ ranging from 0 to $0.1 \mathrm{~s}^{-1}$ for three solute volatilities: (a) $C_{\mathrm{g}}^{*}=10 \mu \mathrm{g} \mathrm{m}^{-3}$, (b) $C_{\mathrm{g}}^{*}=100 \mu \mathrm{g} \mathrm{m}{ }^{-3}$, and (c) $C_{\mathrm{g}}^{*}=1000 \mu \mathrm{g} \mathrm{m}^{-3}$.

Table 2. Bias and error statistics for MOSAIC predictions for the general system simulations.

\begin{tabular}{rrrrrrrrrr}
\hline & \multicolumn{3}{c}{$C_{\mathrm{g}}^{*}=10 \mu \mathrm{g} \mathrm{m}^{-3}$} & \multicolumn{3}{c}{$C_{\mathrm{g}}^{*}=100 \mu \mathrm{g} \mathrm{m}^{-3}$} & \multicolumn{3}{c}{$C_{\mathrm{g}}^{*}=1000 \mu \mathrm{g} \mathrm{m}^{-3}$} \\
\cline { 2 - 10 }$k_{\mathrm{c}}$ & MNB & MNGE & maxNGE & MNB & MNGE & maxNGE & MNB & $\begin{array}{r}\text { MNGE } \\
(\%)\end{array}$ & maxNGE \\
& $(\%)$ & $(\%)$ & $(\%)$ & $(\%)$ & $(\%)$ & $(\%)$ & $(\%)$ & $(\%)$ & $(\%)$ \\
\hline 0 & 0.8 & 0.8 & 8.5 & 0.3 & 0.3 & 2.0 & 0.03 & 0.03 & 0.3 \\
$10^{-4}$ & -1.0 & 2.2 & 6.4 & 0.6 & 0.6 & 1.8 & 0.1 & 0.1 & 0.2 \\
$10^{-3}$ & -3.0 & 3.1 & 5.8 & -0.7 & 1.2 & 3.1 & 0.1 & 0.1 & 0.2 \\
$10^{-2}$ & -3.2 & 3.2 & 5.8 & -2.3 & 2.3 & 4.8 & -0.2 & 0.2 & 0.8 \\
$10^{-1}$ & -2.4 & 2.4 & 5.0 & -0.2 & 1.4 & 2.8 & 1.0 & 1.0 & 1.6 \\
\hline
\end{tabular}

First, the present framework uses a pseudo-first order (PFO) reaction for a condensing solute as a proxy for secondorder chemical reactions that may occur within a particle. The assumption of a PFO reaction for the condensing solute is valid when the preexisting bulk reactant species is uniformly distributed with the depth of the particle, e.g., when the reaction timescale for the reactant species is much longer than that for diffusion. The issue arises when the reaction timescale is much shorter than that for diffusion such that the bulk reactant species is not homogeneously distributed depth-wise (Berkemeier et al., 2013). In such cases, it may be possible to parameterize the PFO reaction rate constant for the condensing solute in terms of its second order rate constant multiplied by the volume average concentration of the preexisting reactant solutes in the particle phase. The detailed finite-difference model using second order reactions can be used to provide guidance for improving and validating the parameterized reactions in the seminumerical framework.

Second, while the present framework allows particles of different sizes and composition to have different bulk diffu- 
sivities, it cannot explicitly treat the potential variation of diffusivity within a given particle of complex morphology. Examples include black carbon or solid ammonium sulfate particles coated with organics as well as particles with nonideal internal mixtures of hydrophobic and hydrophilic organics. The diffusion-reaction process inside such complex and potentially nonspherical particles will again have to be parameterized based on the average bulk properties, with possible guidance from more detailed finite-difference models where applicable.

Third, as mentioned earlier, the new framework can be readily adapted to kinetically partition water soluble organic gases into the particulate aqueous phase if that is the only liquid phase in the particle. However, additional work is needed to extend the present framework to mixed inorganic-organic particles in which water and organics may form separate liquid phases (You et al., 2012).

\section{Results and discussion}

We now apply the updated MOSAIC model to a series of polydisperse aerosol scenarios to investigate the influence of particle-phase reactions, phase state, and solute volatility on SOA partitioning timescale and the evolution of aerosol size distribution. While the exact mechanism(s) responsible for the growth of newly formed particles $(1-10 \mathrm{~nm}$ range) is still unknown, it is suspected to occur via effectively irreversible condensation of very-low-volatility organic species that can overcome the strong Kelvin effect (Pierce et al., 2011). In the present study, we focus on the competitive growth dynamics of the Aitken and accumulation mode particles, as might result after the newly formed particles have grown up to Aitken mode sizes. The Kelvin effect and coagulation are neglected for simplicity. Figure 11 shows the initial aerosol number and volume size distributions used for this exercise. Again, this preexisting aerosol is assumed to be composed of nonvolatile organic species $\left(P_{3}\right)$ of molecular weight $100 \mathrm{~g} \mathrm{~mol}^{-1}$ and density $1 \mathrm{~g} \mathrm{~cm}^{-3}$. The entire size distribution, consisting of an Aitken mode and an accumulation mode, is discretized over 1000 logarithmically spaced size bins (lower boundary of the smallest bin $=0.008 \mu \mathrm{m}$ and the upper boundary of the largest bin $=1 \mu \mathrm{m})$. The total number concentration of particles in the Aitken mode is $6223 \mathrm{~cm}^{-3}$ while that in the accumulation mode is $1139 \mathrm{~cm}^{-3}$; the total aerosol mass concentration is $2 \mu \mathrm{g} \mathrm{m}^{-3}$. Figure 11 also shows the condensational sink $k_{\mathrm{CS}, i, m}=4 \pi R_{\mathrm{p}, m}^{2} N_{m} k_{\mathrm{g}, i, m}$ for each size bin $m$ as a function of $D_{\mathrm{p}}$. For this particular size distribution, the sum of $k_{\mathrm{CS}}$ over all the size bins in the Aitken mode is equal to that in the accumulation mode, so that there is no initial bias in the condensation rate of the solute species towards either mode merely due to differences in the initial condensational sink rates for the two modes. Both closed and general systems scenarios are examined.

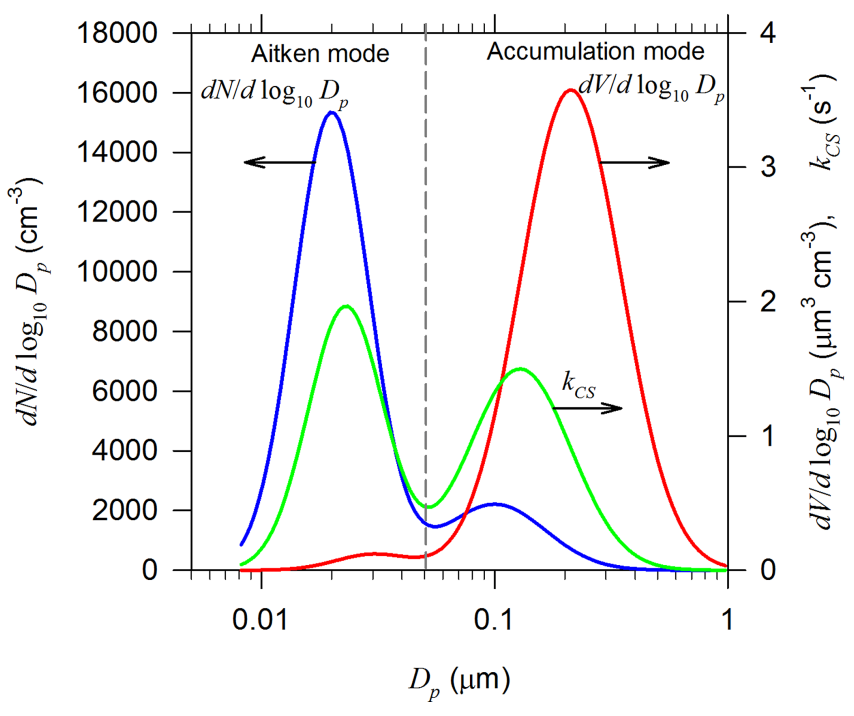

Figure 11. Initial aerosol number and volume size distributions along with the condensational sink $k_{\mathrm{CS}}$. The dashed line demarcates the Aitken mode from the accumulation mode and the initial condensation sink is such that the sum of $k_{\mathrm{CS}}$ over all the size bins in the Aitken mode is equal to that in the accumulation mode.

\subsection{Closed system}

A set of closed system simulations was performed in which the initial organic aerosol was separately exposed to the solute gas $\left(P_{1}\right)$ with three different $C_{\mathrm{g}}^{*}$ values: 10,100 , and $1000 \mu \mathrm{g} \mathrm{m}^{-3}$ (molecular weight $=100 \mathrm{~g} \mathrm{~mol}^{-1}$ ), with an initial gas-phase concentration of $6 \mu \mathrm{g} \mathrm{m}^{-3}$ in each case. For each solute volatility case, the effect of aerosol-phase state was examined using four different $D_{\mathrm{b}}$ values: $10^{-6}, 10^{-12}$, $10^{-13}$, and $10^{-15} \mathrm{~cm}^{2} \mathrm{~s}^{-1}$. In all cases, $k_{\mathrm{c}}$ was set at $0.01 \mathrm{~s}^{-1}$ so that $\tau_{\mathrm{SS}}$ was always less than $\sim 0.7 \mathrm{~min}$ across the entire size distribution. In each case, the simulation was run until the gas-phase solute was completely absorbed and reacted to form a nonvolatile product in the particle phase. Again, the molecular weight and density of the product species $\left(P_{2}\right)$ were assumed to be $100 \mathrm{~g} \mathrm{~mol}^{-1}$ and $1 \mathrm{~g} \mathrm{~cm}^{-3}$, respectively, and all three species $\left(P_{1}, P_{2}\right.$, and $\left.P_{3}\right)$ were assumed to form an ideal solution that participated in the absorption of $P_{1}$ according to Raoult's law. An additional set of reference simulations were performed for two extreme scenarios: (1) instantaneous particle-phase reaction (i.e., $k_{\mathrm{c}} \rightarrow \infty$ ), which is equivalent to solving the nonvolatile solute condensation case (i.e., mechanism \#1), and (2) no particle-phase reaction $\left(k_{\mathrm{c}}=0\right)$, which is referred to as Raoult's law partitioning (i.e., mechanism \#2). In the latter case, the initial gas-phase concentrations for the different $C_{\mathrm{g}}^{*}$ subcases were increased such that $6 \mu \mathrm{g} \mathrm{m}^{-3}$ of solute was partitioned into the particle phase at steady state (i.e., at equilibrium) in each case. 

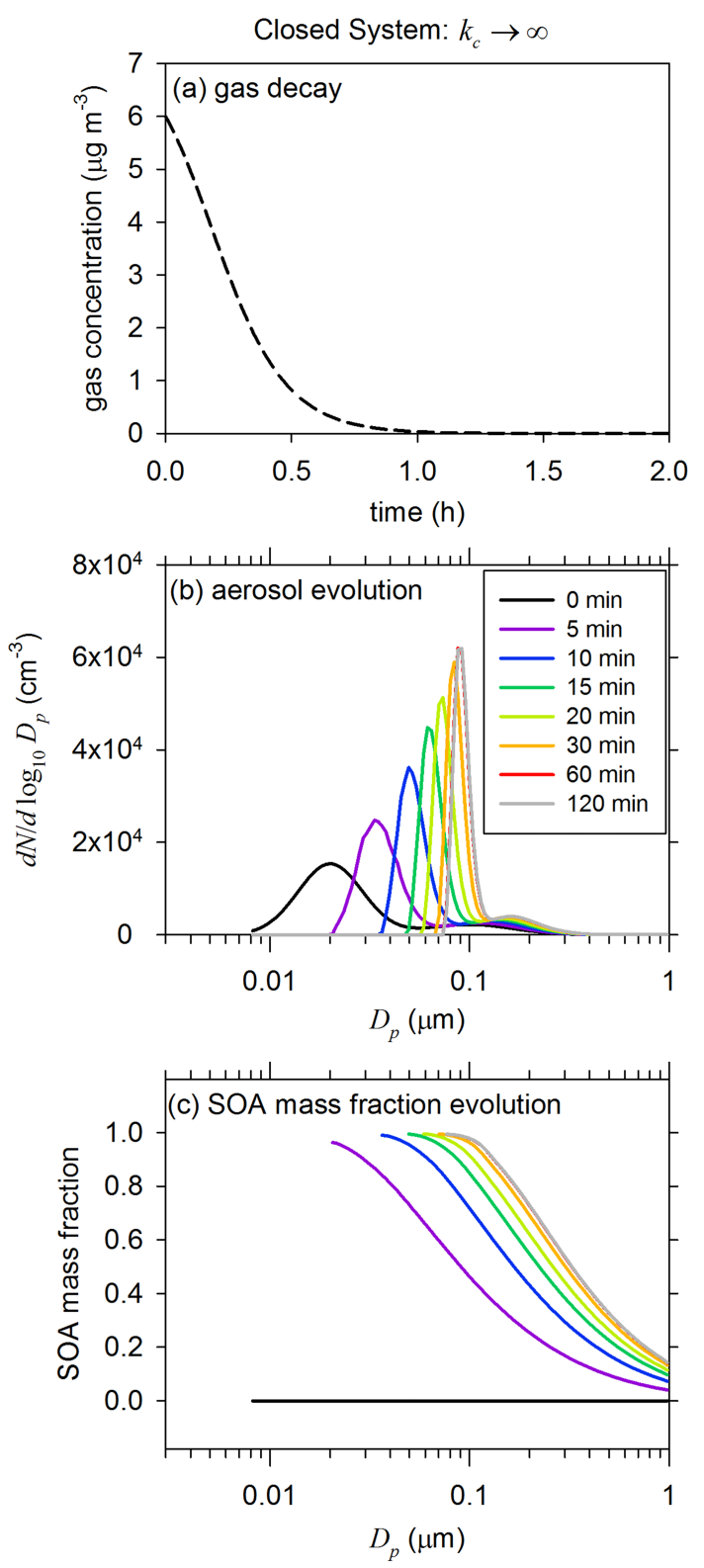

Figure 12. Results for the instantaneous reaction reference case $\left(k_{\mathrm{c}} \rightarrow \infty\right.$; equivalent to nonvolatile solute condensation): (a) gasphase concentration decay, (b) temporal evolution of aerosol size distribution, and (c) temporal evolution of the mass fraction of newly formed SOA.

\subsubsection{Reference cases}

We shall first discuss the results of the closed system reference cases. Figure 12 shows the gas-phase decay and the corresponding temporal evolution of aerosol size distribution and mass fraction of newly formed SOA for the instantaneous particle-phase reaction case. Here, gas-particle partitioning is independent of the particle-phase state and is governed entirely by gas-phase diffusion limitation. Vapor concentration is completely depleted in about $1 \mathrm{~h}$, and aerosol size distribution evolution displays the well-known narrowing characteristics as the small particles grow faster (more precisely, have greater $\mathrm{d} \ln D_{\mathrm{p}} / \mathrm{d} t$ ) than the large ones (Zhang et al., 2012). Consequently, the mass fraction of the newly formed SOA in smaller particles is much higher than in the larger ones. Note that in the SOA mass fraction panel, the left-most point on each line with mass fraction $\approx 1$ corresponds to the smallest initial particles $\left(D_{\mathrm{p}}=0.008 \mu \mathrm{m}\right.$ at $\left.t=0\right)$.

In contrast, aerosol evolution due to Raoult's law partitioning depends on both solute volatility and particle-phase state. Figure 13 shows the gas-phase concentration decay and the corresponding aerosol size distribution and SOA mass fraction evolution for the less volatile solute with $C_{\mathrm{g}}^{*}=10 \mu \mathrm{g} \mathrm{m}^{-3}$. The effect of phase state is illustrated with two bulk diffusivities: $D_{\mathrm{b}}=10^{-6}$ and $10^{-15} \mathrm{~cm}^{2} \mathrm{~s}^{-1}$. In the case with liquid particles $\left(D_{\mathrm{b}}=10^{-6} \mathrm{~cm}^{2} \mathrm{~s}^{-1}\right)$ there is negligible resistance to mass transfer within the particle (refer to Fig. 6a), and as a result the vapor concentration rapidly decreases during the first $1 \mathrm{~h}$ and reaches a steady state in about $7.5 \mathrm{~h}$. In the first $\sim 20 \mathrm{~min}$, the size distribution exhibits the narrowing of the Aitken mode similar to that seen in gasphase diffusion-limited growth, although not as intense. The SOA mass fraction reaches up to 0.97 in small particles while it is only about 0.25 in the large particles. However, as the vapor concentration decreases further, the peak of the size distribution begins to decrease and the width broadens due to evaporation from small particles while the large particles continue to grow (Zhang et al., 2012). The SOA mass fraction in small particles decreases to 0.75 , while it gradually increases to 0.75 in the large particles. The vapor concentration remains steady while this interparticle mass transfer (via the gas phase) occurs over a relatively longer period $(\sim 480 \mathrm{~h})$ until the entire aerosol size distribution reaches equilibrium.

Similar behavior is seen in the case with semisolid particles $\left(D_{\mathrm{b}}=10^{-15} \mathrm{~cm}^{2} \mathrm{~s}^{-1}\right)$, although the timescale over which it occurs is relatively longer due to much higher particle-phase diffusion limitation. While the vapor concentration declines rapidly in the beginning (e-folding timescale of $16.5 \mathrm{~h}$ ), it takes about $175 \mathrm{~h}$ to reach the steady state and more than $400 \mathrm{~h}$ for the aerosol size distribution to reach equilibrium. Also, because the particle-phase diffusion limitation is much less in small particles than the large ones (refer to Fig. 6a), the Aitken mode exhibits more intense narrowing and a higher peak (at about $1 \mathrm{~h}$ ) than seen in liquid particles. Then, again, as the vapor concentration decreases further, the width broadens and the peak decreases due to evaporation of small particles while the large ones continue to grow more slowly. The final aerosol size distribution and SOA mass fraction across the size spectrum are identical (within numerical errors) to those obtained in the liquid-particle case.

Figure 14 shows the results for the more volatile solute with $C_{\mathrm{g}}^{*}=1000 \mu \mathrm{g} \mathrm{m}^{-3}$. In the case with liquid particles $\left(D_{\mathrm{b}}=10^{-6} \mathrm{~cm}^{2} \mathrm{~s}^{-1}\right)$, the vapor concentration reaches the 

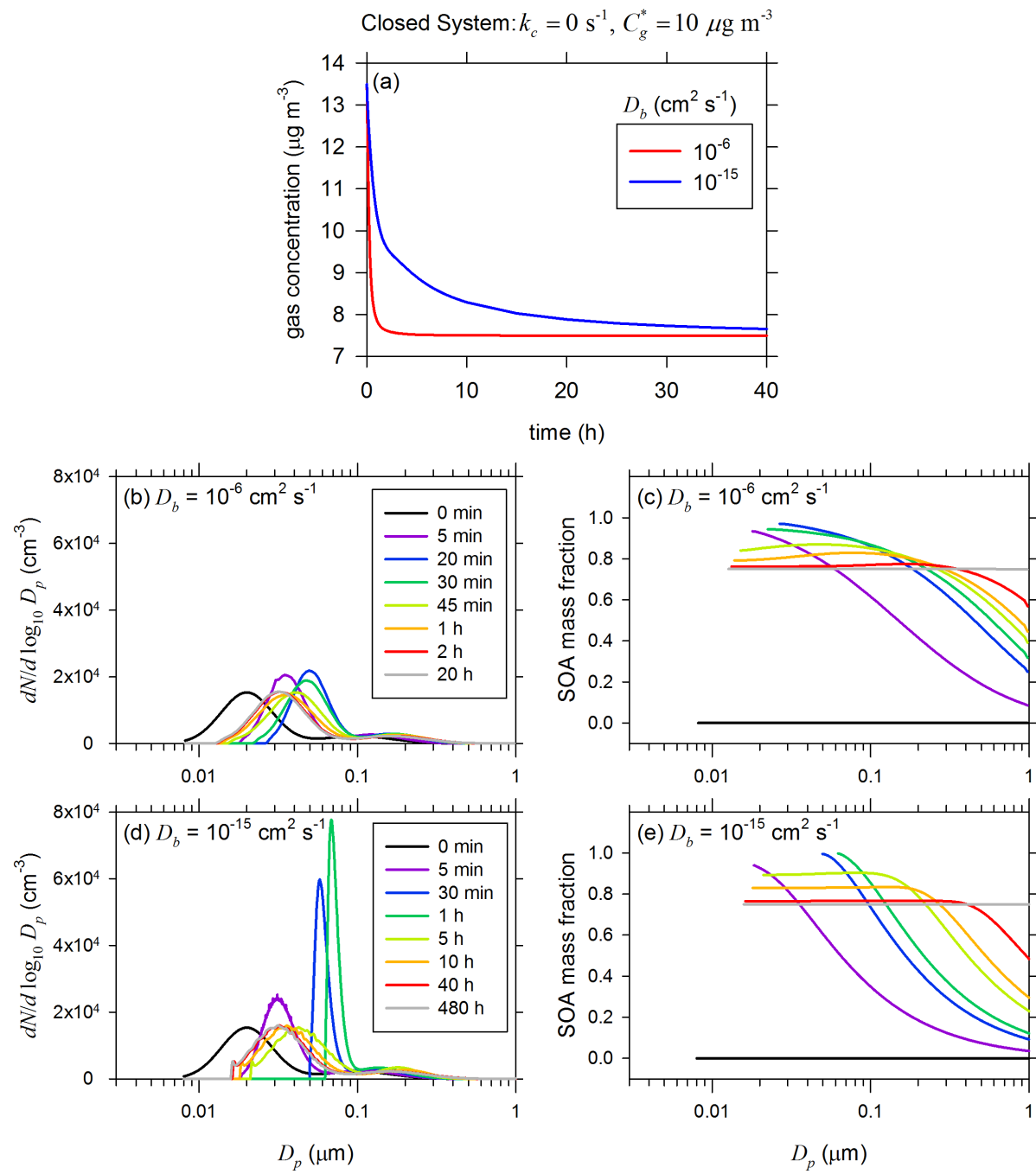

Figure 13. Results for kinetic SOA partitioning due to Raoult's law $\left(k_{\mathrm{c}}=0 \mathrm{~s}^{-1}\right)$ for $C_{\mathrm{g}}^{*}=10 \mu \mathrm{g} \mathrm{m}^{-3}$ : (a) gas-phase concentration decay for $D_{\mathrm{b}}=10^{-6}$ and $10^{-15} \mathrm{~cm}^{2} \mathrm{~s}^{-1}$, (b) aerosol evolution for $D_{\mathrm{b}}=10^{-6} \mathrm{~cm}^{2} \mathrm{~s}^{-1}$, (c) SOA mass fraction evolution for $D_{\mathrm{b}}=10^{-6} \mathrm{~cm}^{2} \mathrm{~s}^{-1}$, (d) aerosol evolution for $D_{\mathrm{b}}=10^{-15} \mathrm{~cm}^{2} \mathrm{~s}^{-1}$, and (e) SOA mass fraction evolution for $D_{\mathrm{b}}=10^{-15} \mathrm{~cm}^{2} \mathrm{~s}^{-1}$. In both cases, the final (i.e., equilibrium) concentration of the newly formed SOA is $6 \mu \mathrm{g} \mathrm{m}{ }^{-3}$.

steady state in just $20 \mathrm{~min}$ (vs. $7.5 \mathrm{~h}$ for $C_{\mathrm{g}}^{*}=10 \mu \mathrm{g} \mathrm{m}^{-3}$ ) while it takes nearly $400 \mathrm{~h}$ (vs. $175 \mathrm{~h}$ for $C_{\mathrm{g}}^{*}=10 \mu \mathrm{g} \mathrm{m}^{-3}$ ) in the case with semisolid particles $\left(D_{\mathrm{b}}=10^{-15} \mathrm{~cm}^{2} \mathrm{~s}^{-1}\right)$. Again, the final aerosol size distribution and SOA mass fraction solutions at equilibrium are identical to those obtained for the $C_{\mathrm{g}}^{*}=10 \mu \mathrm{g} \mathrm{m}^{-3}$ cases, but their temporal evolutions are quite different. In the case with liquid particles, the width of the aerosol size distribution does not narrow and the peak height remains the same as the particles grow. This is because the small particles quickly attain a quasi-equilibrium state with the more volatile solute. Consequently, the SOA mass fraction in the small particles quickly reaches the equilibrium value of 0.75 (instead of overshooting as seen for $C_{\mathrm{g}}^{*}=10 \mu \mathrm{g} \mathrm{m}^{-3}$ ) while the larger particles catch up slightly more slowly. The entire size distribution reaches equilibrium within $1 \mathrm{~h}$.

In the case with semisolid particles, the Aitken mode size distribution narrows (similar to that seen in Fig. 13a) in the first few minutes, but broadens back within $30 \mathrm{~min}$. Again, the SOA mass fraction in small particles quickly reaches the equilibrium value of 0.75 , while it still takes $\sim 480 \mathrm{~h}$ for the large particles in the spectrum to reach equilibrium due to the significant diffusion limitation in the particle phase.

\subsubsection{Reactive partitioning cases}

We now present results for the closed-system reactive partitioning cases with $k_{\mathrm{c}}=0.01 \mathrm{~s}^{-1}$. Fig. 15 shows vapor concentration decay for each of the three solute volatility cases $\left(C_{\mathrm{g}}^{*}=10,100\right.$, and $\left.1000 \mu \mathrm{g} \mathrm{m}^{-3}\right)$ for $D_{\mathrm{b}}$ values ranging from 

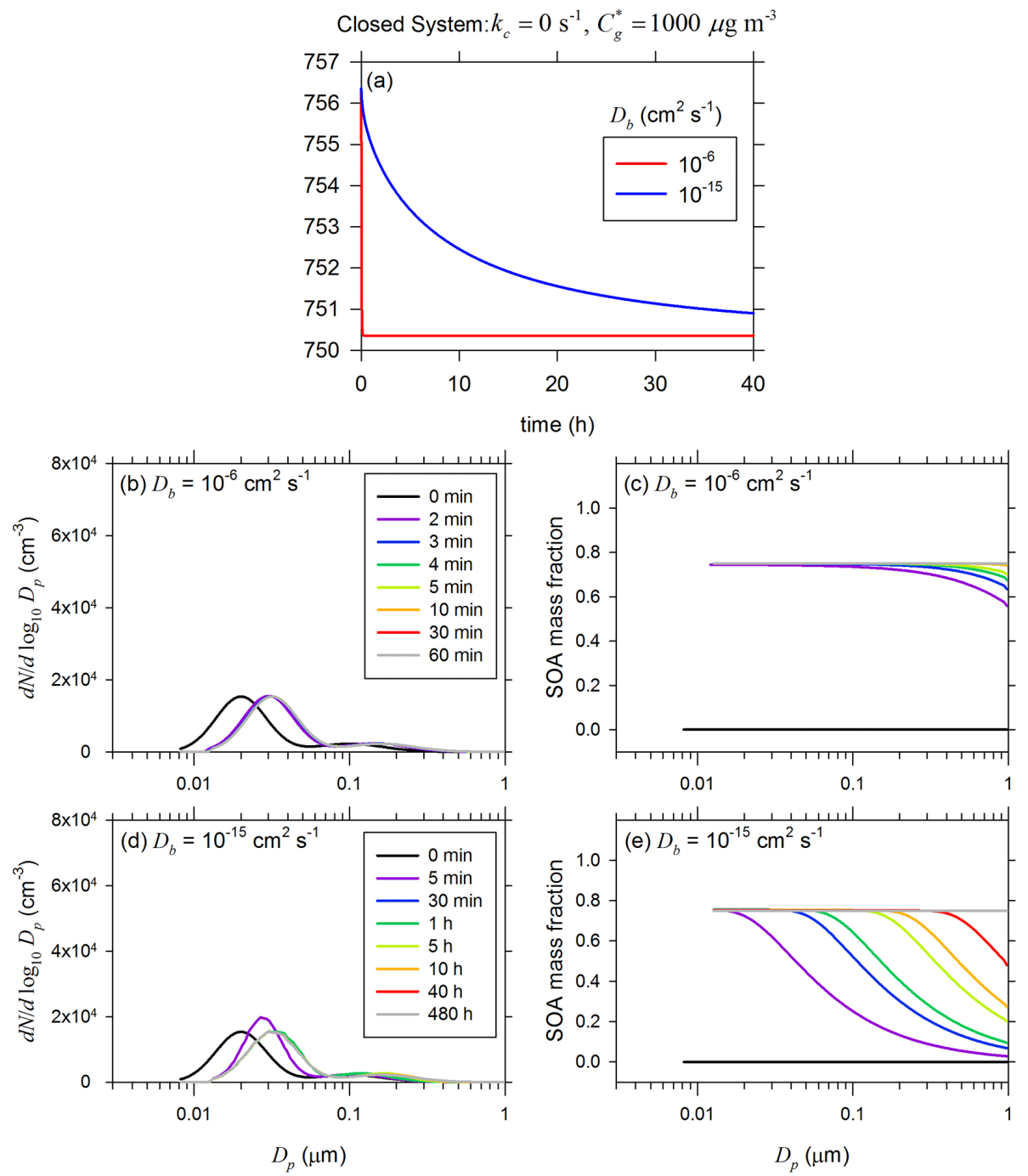

Figure 14. Same as Fig. 13, except $C_{\mathrm{g}}^{*}=1000 \mu \mathrm{g} \mathrm{m}^{-3}$.

$10^{-6}$ to $10^{-15} \mathrm{~cm}^{2} \mathrm{~s}^{-1}$. It also shows a plot of the e-folding timescale $\left(\tau_{\mathrm{g}}\right)$ for the decay as a function of $D_{\mathrm{b}}$ for the different volatilities. Each plot includes the reference case of instantaneous reaction for comparison. Unlike in Raoult's law partitioning, the vapor concentration always decays to zero in reactive partitioning and the decay rate slows down with increase in $C_{\mathrm{g}}^{*}$. The vapor decay rate also slows down with decrease in $D_{\mathrm{b}}$ and it is especially sensitive to $D_{\mathrm{b}}$ in semisolid particles.

Figure 16 illustrates the effects of the different $C_{\mathrm{g}}^{*}$ and $D_{\mathrm{b}}$ values on the final aerosol size distribution. The final results for the reference cases of instantaneous reaction and Raoult's law partitioning are also shown for easy comparison. In the case of $C_{\mathrm{g}}^{*}=10 \mu \mathrm{g} \mathrm{m}^{-3}$, the Aitken mode exhibits significant narrowing for all values of $D_{\mathrm{b}}$. The narrowing becomes more pronounced for $D_{\mathrm{b}}<10^{-13} \mathrm{~cm}^{2} \mathrm{~s}^{-1}$ with the shape of the entire size distribution for $D_{\mathrm{b}}=10^{-15} \mathrm{~cm}^{2} \mathrm{~s}^{-1}$ being nearly identical to that for the instantaneous reaction refer- ence case. Further decrease in $D_{\mathrm{b}}$ will produce even more narrowing. Since there is negligible particle-phase diffusion limitation for $D_{\mathrm{b}}>10^{-10} \mathrm{~cm}^{2} \mathrm{~s}^{-1}(Q \approx 1$; Fig. 7c), the size distribution of liquid aerosol narrows because its initial evolution (in the case of low volatility solutes) resembles that of gas-phase diffusion-limited growth, and the particle-phase reaction rate is fast enough to transform the absorbed solute to a nonvolatile product before it can evaporate. For $D_{\mathrm{b}}$ $<10^{-13} \mathrm{~cm}^{2} \mathrm{~s}^{-1}$, the steep gradient in $Q$ across the size distribution results in significantly lower surface concentrations over small semisolid particles compared to the large ones. The small semisolid particles therefore grow even faster than the large ones compared to the corresponding liquid aerosol case, causing relatively more intense narrowing of the size distribution.

As the solute $C_{\mathrm{g}}^{*}$ increases to 100 and $1000 \mu \mathrm{g} \mathrm{m}^{-3}$, liquid particles tend to attain quasi-equilibrium with the gas phase relatively faster than the solute reacts within the particle. As 

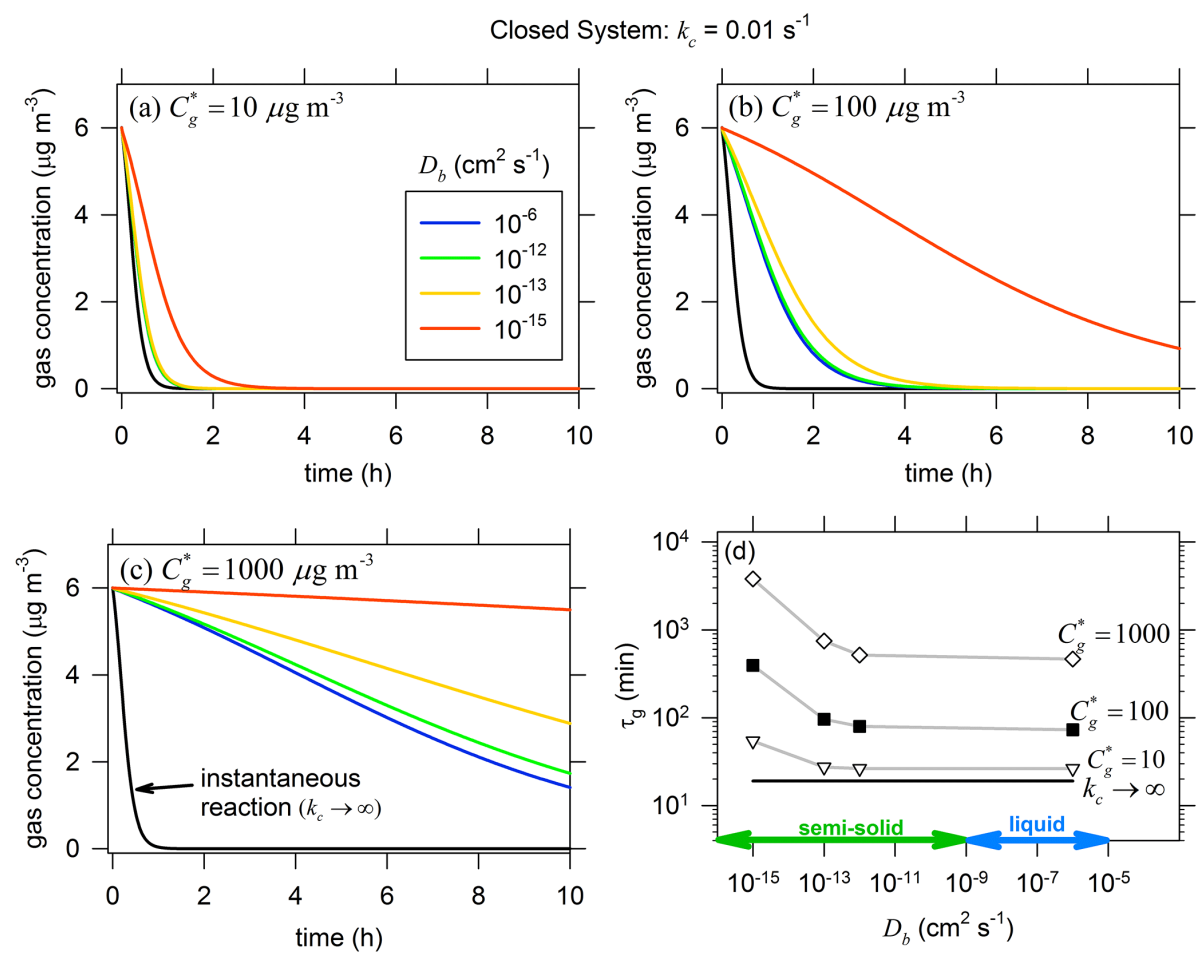

Figure 15. Gas-phase concentration decay due to kinetic SOA partitioning with particle-phase reaction $\left(k_{\mathrm{c}}=0.01 \mathrm{~s}^{-1}\right)$ for bulk diffusivities ranging from $10^{-6}$ to $10^{-15} \mathrm{~cm}^{2} \mathrm{~s}^{-1}$ and three gas volatilities: (a) $C_{\mathrm{g}}^{*}=10 \mu \mathrm{g} \mathrm{m}^{-3}$, (b) $C_{\mathrm{g}}^{*}=100 \mu \mathrm{g} \mathrm{m}{ }^{-3}$, and (c) $C_{\mathrm{g}}^{*}=1000 \mu \mathrm{g} \mathrm{m}{ }^{-3}$. Each plot also shows gas-phase concentration decay for the reference case of instantaneous reaction (black line, $k_{\mathrm{c}} \rightarrow \infty$ ). In each case, the final concentration of the newly formed SOA is $6 \mu \mathrm{g} \mathrm{m}^{-3}$. Panel (d) shows the plot of gas-phase concentration decay timescale $\left(\tau_{\mathrm{g}}\right)$ as a function of $D_{\mathrm{b}}$ for the different gas volatilities.

a result, the final size distributions for $D_{\mathrm{b}} \leq 10^{-12} \mathrm{~cm}^{2} \mathrm{~s}^{-1}$ progressively resemble that of the Raoult's law partitioning case. However, significant narrowing is still seen for $D_{\mathrm{b}}=10^{-15} \mathrm{~cm}^{2} \mathrm{~s}^{-1}$ due to the steep gradient in $Q$ across the size distribution, which causes the small semisolid particles to grow much faster than the large semisolid ones when compared to the corresponding liquid aerosol case where $Q \approx 1$ across the entire size distribution. In general, the final size distribution shape tends to be closer to that for instantaneous reaction case for lower $C_{\mathrm{g}}^{*}$ and $D_{\mathrm{b}}$ values and higher $k_{\mathrm{c}}$ values, while it tends to be closer to that for Raoult's law partitioning for higher $C_{\mathrm{g}}^{*}$ and $D_{\mathrm{b}}$ and lower $k_{\mathrm{c}}$.

Figure 17 illustrates the influence of $C_{\mathrm{g}}^{*}$ and $D_{\mathrm{b}}$ values on the final SOA mass fraction size distribution. Curves for the two reference cases are also included for comparison. In the case of $C_{\mathrm{g}}^{*}=10 \mu \mathrm{g} \mathrm{m}^{-3}$, the curves for all $D_{\mathrm{b}}$ values are similar to that of the instantaneous reference case due to appreciable narrowing of the size distribution. But as $C_{\mathrm{g}}^{*}$ increases, the SOA mass fraction curves progressively become more uniform for $D_{\mathrm{b}}=10^{-6} \mathrm{~cm}^{2} \mathrm{~s}^{-1}$ while they remain nonuniform for $D_{\mathrm{b}}<10^{-12} \mathrm{~cm}^{2} \mathrm{~s}^{-1}$ for particles with $D_{\mathrm{p}}>0.2 \mu \mathrm{m}$. In all $C_{\mathrm{g}}^{*}$ cases, the SOA mass fraction curves for $D_{\mathrm{b}}=10^{-15} \mathrm{~cm}^{2} \mathrm{~s}^{-1}$ closely resemble the instantaneous reaction case.

\subsection{General system}

A set of general system simulations was performed in which the initial organic aerosol was separately exposed to solutes with $C_{\mathrm{g}}^{*}=10,100$, and $1000 \mu \mathrm{g} \mathrm{m}^{-3}$ at a moderate but constant gas-phase source rate of $\gamma=0.6 \mu \mathrm{g} \mathrm{m}^{-3} \mathrm{~h}^{-1}$ in each case. The effect of aerosol-phase state was examined using two different $D_{\mathrm{b}}$ values: $10^{-6}$ and $10^{-15} \mathrm{~cm}^{2} \mathrm{~s}^{-1}$. For each combination of $C_{\mathrm{g}}^{*}$ and $D_{\mathrm{b}}$ values, the effect of particle-phase reaction was examined for $k_{\mathrm{c}}=0.01,0.1,1$, and $\infty \mathrm{s}^{-1}$. Each simulation was $12 \mathrm{~h}$ long.

Figure 18 shows the time evolutions of total SOA mass concentration for liquid particles $\left(D_{\mathrm{b}}=10^{-6} \mathrm{~cm}^{2} \mathrm{~s}^{-1}\right)$ with different solute $C_{\mathrm{g}}^{*}$ values and the corresponding final aerosol size distributions at $t=12 \mathrm{~h}$. In the case with $C_{\mathrm{g}}^{*}=10 \mu \mathrm{g} \mathrm{m}^{-3}$, the SOA formation rate is essentially the same for $k_{\mathrm{c}} \geq 0.01 \mathrm{~s}^{-1}$, with a total of about $7 \mu \mathrm{g} \mathrm{m}^{-3}$ SOA formed at the end of $12 \mathrm{~h}$. Appreciable narrowing of the Aitken mode size distribution occurs for $k_{\mathrm{c}}=0.01 \mathrm{~s}^{-1}$, which is qualitatively similar to the closed system results for $D_{\mathrm{b}}=10^{-6} \mathrm{~cm}^{2} \mathrm{~s}^{-1}$ shown previously in Fig. 16a. Higher $k_{\mathrm{c}}$ values produce even more intense narrowing of the Aitken mode and the shapes are practically indistinguishable from that for instantaneous reaction. As $C_{\mathrm{g}}^{*}$ increases, the so- 


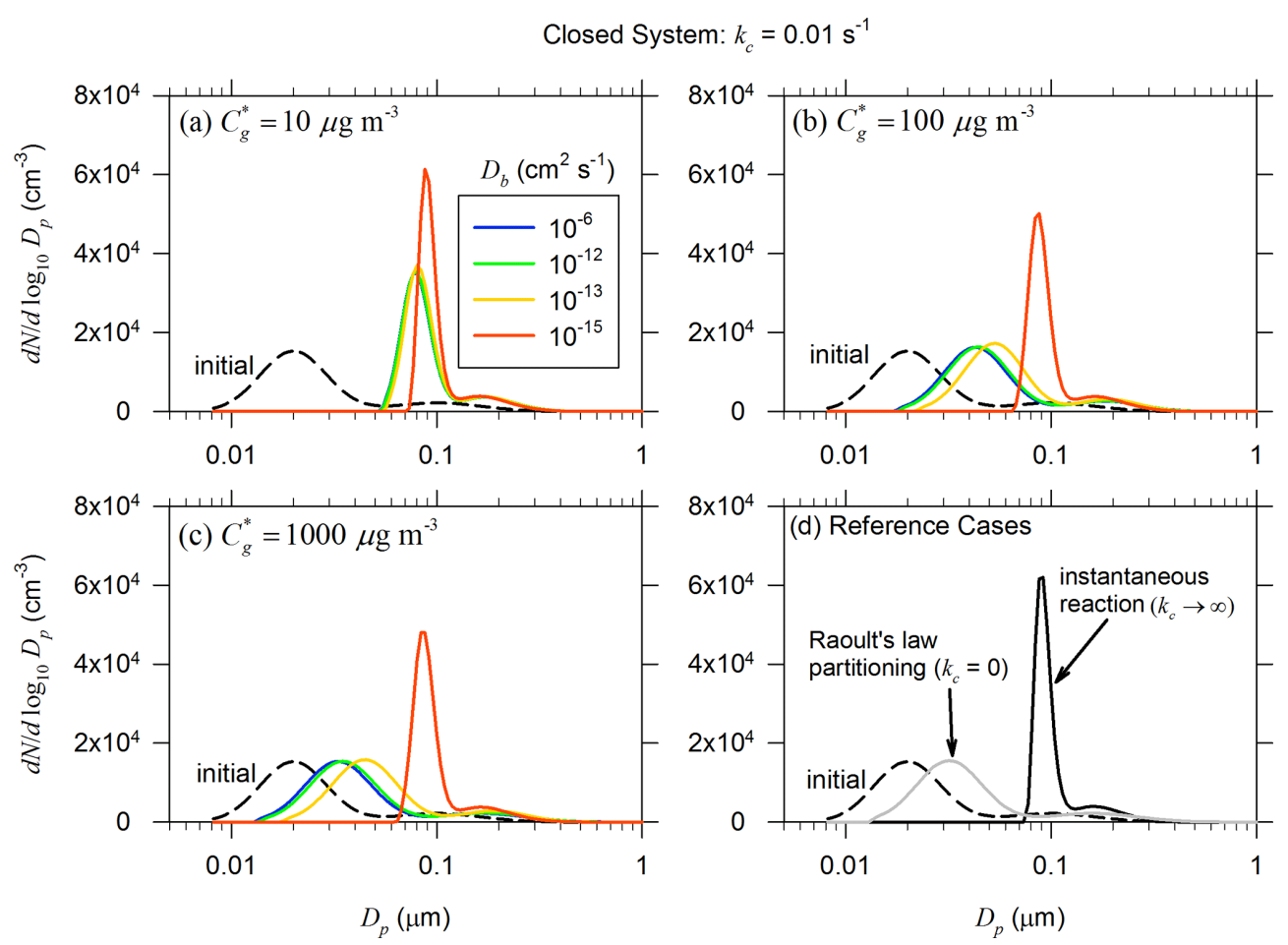

Figure 16. Initial (dashed line) and final (solid lines) aerosol number size distribution due to Raoult's law gas-particle partitioning coupled with particle-phase reaction $\left(k_{\mathrm{c}}=0.01 \mathrm{~s}^{-1}\right)$ for bulk diffusivities ranging from $10^{-6}$ to $10^{-15} \mathrm{~cm}^{2} \mathrm{~s}^{-1}$ and three gas volatilities: (a) $C_{\mathrm{g}}^{*}=10 \mu \mathrm{g} \mathrm{m}^{-3}$, (b) $C_{\mathrm{g}}^{*}=100 \mu \mathrm{g} \mathrm{m}^{-3}$, and (c) $C_{\mathrm{g}}^{*}=1000 \mu \mathrm{g} \mathrm{m}^{-3}$. Panel (d) shows the final size distributions for the two reference cases: instantaneous reaction (black line; $k_{\mathrm{c}} \rightarrow \infty$ ) and Raoult's law partitioning (gray line; $k_{\mathrm{c}}=0$ ) for any $D_{\mathrm{b}}$ and $C_{\mathrm{g}}^{*}>0$. As illustrated in Fig. 15, the time required to reach the final state differs significantly for different cases, but the final SOA formed in each case is $6 \mu \mathrm{g} \mathrm{m}^{-3}$.

lute vapor tends towards quasi-equilibrium with the particle phase for low $k_{\mathrm{c}}$ values. As a result, the SOA formation rate slows down and the Aitken mode shapes for $k_{\mathrm{c}}=0.01$ $\mathrm{s}^{-1}$ qualitatively tend to resemble that of Raoult's law partitioning in the closed system shown previously in Fig. 16b, c. But as $k_{\mathrm{c}}$ increases, the mass transfer becomes progressively more gas-phase-diffusion limited, which results in faster growth of the smaller particles and, therefore, increasing narrowing of the Aitken mode.

Figure 19 shows the results for semisolid particles $\left(D_{\mathrm{b}}=10^{-15} \mathrm{~cm}^{2} \mathrm{~s}^{-1}\right)$. It is seen that the presence of significant particle-phase diffusion limitation slows down the SOA formation rates, especially with increasing $C_{\mathrm{g}}^{*}$ and decreasing $k_{\mathrm{c}}$. The marked size-dependence of the diffusion limitation also gives rise to more intense narrowing of the size distribution than seen in the corresponding liquid-particle cases.

In the absence of a particle-phase reaction (i.e., $k_{\mathrm{c}}=0$, not shown in the figures) only $\sim 1.2 \mu \mathrm{g} \mathrm{m}^{-3}$ of SOA is formed in both the liquid and semisolid aerosol cases after $12 \mathrm{~h}$ when $C_{\mathrm{g}}^{*}=10 \mu \mathrm{g} \mathrm{m}^{-3}$ while negligibly small amounts of SOA are formed for higher $C_{\mathrm{g}}^{*}$ values. Overall, the growth characteristics seen in the general system cases considered here are qualitatively similar to the closed system results, although significant differences between them can occur if the va- por source rate is appreciably different than the one used in the present study. For instance, if the vapor source rate is very small, then the growth characteristics will tend towards Raoult's law partitioning. In contrast, if the vapor source rate is very high, then the growth will tend to become gas-phase diffusion limited.

\section{Summary and implications}

We have extended the computationally efficient MOSAIC aerosol model (Zaveri et al., 2008) to include a new framework for kinetic SOA partitioning that takes into account solute volatility, gas-phase diffusion, interfacial mass accommodation, particle-phase diffusion, and particle-phase reaction. The framework uses a combination of (a) an analytical quasi-steady-state treatment for the diffusion-reaction process within the particle phase for fast-reacting organic solutes such that the timescales ( $\left.\tau_{\mathrm{QSS}}\right)$ for their particle-phase concentrations to reach quasi-steady state are shorter than $1 \mathrm{~min}$, and (b) a two-film theory approach for slow- and nonreacting organic solutes. The updated MOSAIC model was successfully validated against a benchmark finite-difference solution of the diffusion-reaction problem. MOSAIC already predicts liquid water associated with inorganic species, and 


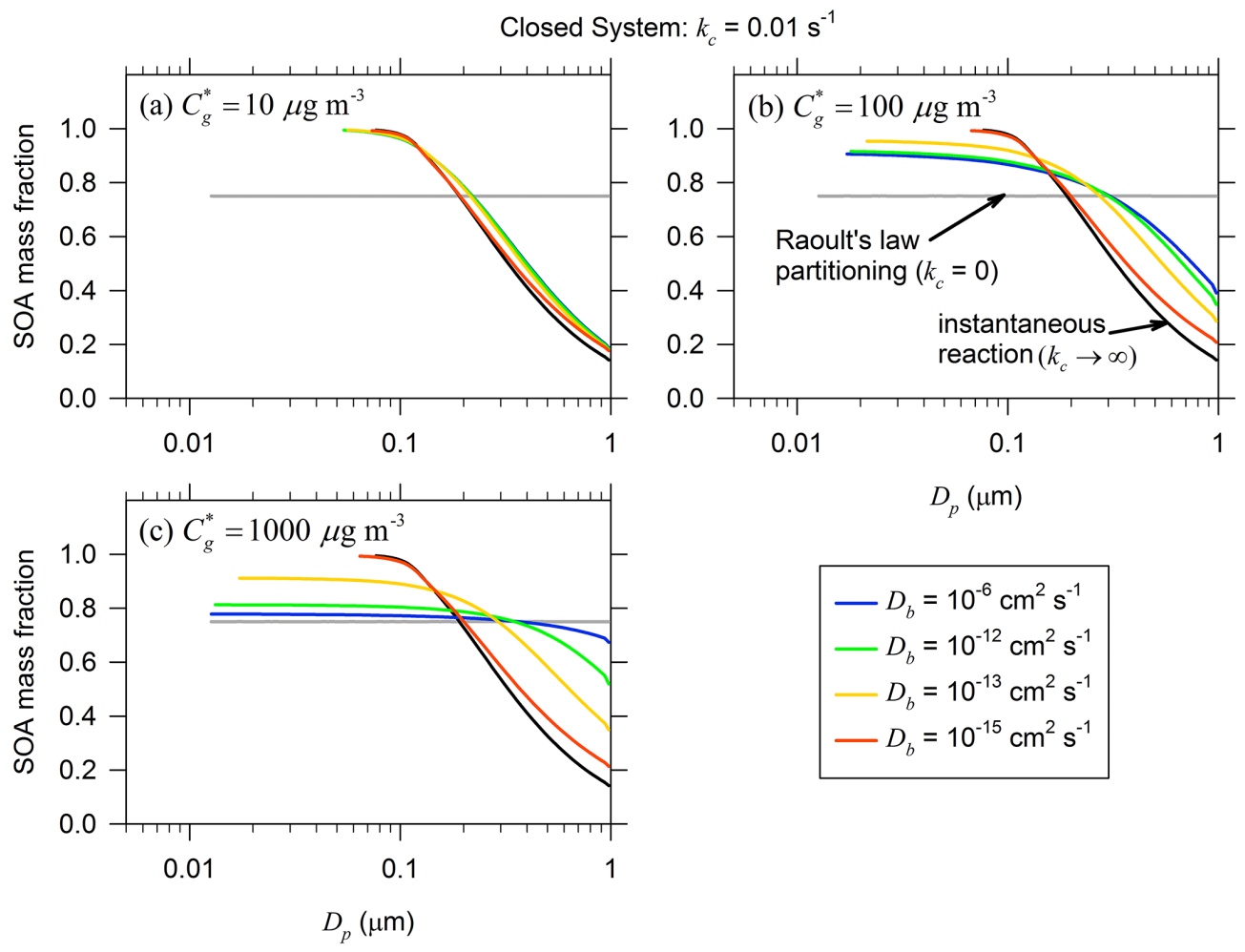

Figure 17. Final size distributions of the newly formed SOA mass fraction for different $D_{\mathrm{b}}$ values and (a) $C_{\mathrm{g}}^{*}=10 \mu \mathrm{g} \mathrm{m}^{-3}$, (b) $C_{\mathrm{g}}^{*}=100 \mu \mathrm{g} \mathrm{m}^{-3}$, and (c) $C_{\mathrm{g}}^{*}=1000 \mu \mathrm{g} \mathrm{m}^{-3}$. Each panel also shows the reference plots for instantaneous reaction (black line; $k_{\mathrm{c}} \rightarrow \infty$ ) and for Raoult's law partitioning (gray line; $k_{\mathrm{c}}=0 \mathrm{~s}^{-1}$ ) for any $D_{\mathrm{b}}$ and $C_{\mathrm{g}}^{*}>0$.

the new framework can be readily adapted to kinetically partition water soluble organic gases into the particulate aqueous phase if that is the only liquid phase in the particle. Additional work is needed to treat mass transfer of gas-phase species to mixed inorganic-organic particles that experience liquid-liquid phase separation (You et al., 2012). The proposed framework is amenable for use in regional and global atmospheric models, although it currently awaits specification of the various gas- and particle-phase chemistries and the related physicochemical properties that are important for SOA formation.

In the present study, we have applied the model to evaluate the effects of solute volatility $\left(C_{\mathrm{g}}^{*}\right)$, particle-phase bulk diffusivity $\left(D_{\mathrm{b}}\right)$, and particle-phase chemical reaction, as exemplified by the pseudo-first-order rate constant $\left(k_{\mathrm{c}}\right)$, on kinetic SOA partitioning. We focus on the competitive growth dynamics of the Aitken and accumulation mode particles due to condensation while the Kelvin effect and coagulation are neglected for simplicity. Our analysis shows that the timescale of SOA partitioning and the associated evolution of aerosol number and composition size distributions depend on the complex interplay between $C_{\mathrm{g}}^{*}, D_{\mathrm{b}}$, and $k_{\mathrm{c}}$, each of which can vary over several orders of magnitude. The key findings and their implications are summarized below.
1. In the case of instantaneous particle-phase reaction $\left(k_{\mathrm{c}} \rightarrow \infty\right)$, SOA partitioning is mathematically equivalent to irreversible condensation of nonvolatile organic vapors $\left(C_{\mathrm{g}}^{*}=0\right.$; mechanism \#1). Mass transfer is gasphase diffusion limited, which produces the well-known narrowing of the aerosol size distribution as small particles grow faster than the large ones (Zhang et al., 2012).

2. In the case of nonreactive reversible absorption of semivolatile and volatile organic vapors by Raoult's law $\left(k_{\mathrm{c}}=0\right.$; mechanism \#2), the final partitioning across the size distribution is volume-controlled (Zhang et al., 2012) and the partitioning timescale increases with decrease in $C_{\mathrm{g}}^{*}$ and $D_{\mathrm{b}}$ (Shiraiwa and Seinfeld, 2012b). In the absence of the Kelvin effect and coagulation, the mole fraction of SOA across the final size distribution at equilibrium is identical. As a result, the size distribution simply shifts along the diameter axis while its shape (mode widths and peak heights) remains unchanged. However, in a closed system, this mechanism may produce temporary narrowing of the size distribution as small particles reach quasi-equilibrium faster than the large ones (Zhang et al., 2012). The narrowing is especially pronounced if the preexisting particles are highly viscous semisolids $\left(D_{\mathrm{b}}<10^{-12} \mathrm{~cm}^{2} \mathrm{~s}^{-1}\right)$ and the initial 
General System: $D_{b}=10^{-6} \mathrm{~cm}^{2} \mathrm{~s}^{-1}, \gamma=0.6 \mu \mathrm{g} \mathrm{m}^{-3} \mathrm{~h}^{-1}$
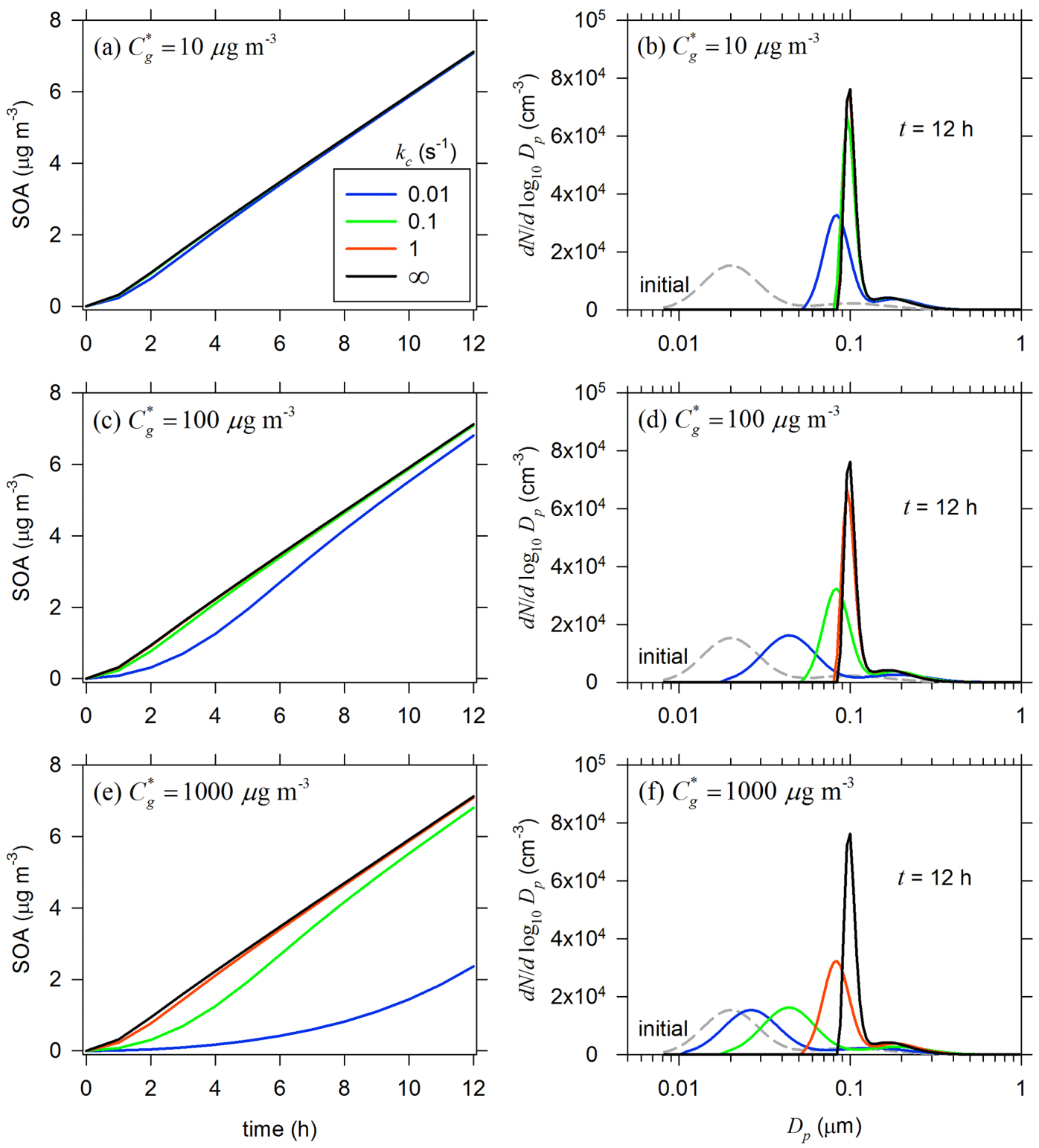

Figure 18. Temporal evolution of total SOA mass concentration (left column) and aerosol size distribution (right column) at $t=12 \mathrm{~h}$ for $D_{\mathrm{b}}=10^{-6} \mathrm{~cm}^{2} \mathrm{~s}^{-1}, \gamma=0.6 \mu \mathrm{g} \mathrm{m}{ }^{-3} \mathrm{~h}^{-1}, k_{\mathrm{c}}=0.01$ to $\infty \mathrm{s}^{-1}$, and three different solute volatilities: (a, b) $C_{\mathrm{g}}^{*}=10 \mu \mathrm{g} \mathrm{m}{ }^{-3}$, (c, d) $C_{\mathrm{g}}^{*}=100 \mu \mathrm{g} \mathrm{m}^{-3}$, and $(\mathbf{e}, \mathbf{f}) C_{\mathrm{g}}^{*}=1000 \mu \mathrm{g} \mathrm{m}^{-3}$.

gas-phase concentration is appreciably higher than the solute vapor volatility. Also, while the vapor concentration may reach a steady-state relatively quickly, the timescale for the "narrowed" aerosol size distribution to relax back to its final (equilibrium) shape can be on the order of a few minutes to days, depending on the values of $D_{\mathrm{b}}$ and $C_{\mathrm{g}}^{*}$.

3. In the case of reactive partitioning (finite $k_{\mathrm{c}}$; mechanism \#3), the size distribution experiences permanent narrowing (Shiraiwa et al., 2013a), which can be especially pronounced for low values of $C_{\mathrm{g}}^{*}\left(\sim 10 \mu \mathrm{g} \mathrm{m}^{-3}\right.$ and less $)$ and $D_{\mathrm{b}}\left(<10^{-13} \mathrm{~cm}^{2} \mathrm{~s}^{-1}\right)$ and high values of $k_{\mathrm{c}}$ $\left(\sim 0.01 \mathrm{~s}^{-1}\right.$ and higher). As $C_{\mathrm{g}}^{*}$ and $D_{\mathrm{b}}$ increase and $k_{\mathrm{c}}$ decreases, the narrowing reduces and the final size distribution tends to resemble that produced by mechanism \#2. But unlike in mechanism \#2, the gas-phase concentration of the solute eventually decays to zero and the partitioning timescale increases with increase in $C_{\mathrm{g}}^{*}$ and decrease in $D_{\mathrm{b}}$ and $k_{\mathrm{c}}$. The partitioning timescale and the shape of the size distribution are especially sensi- 

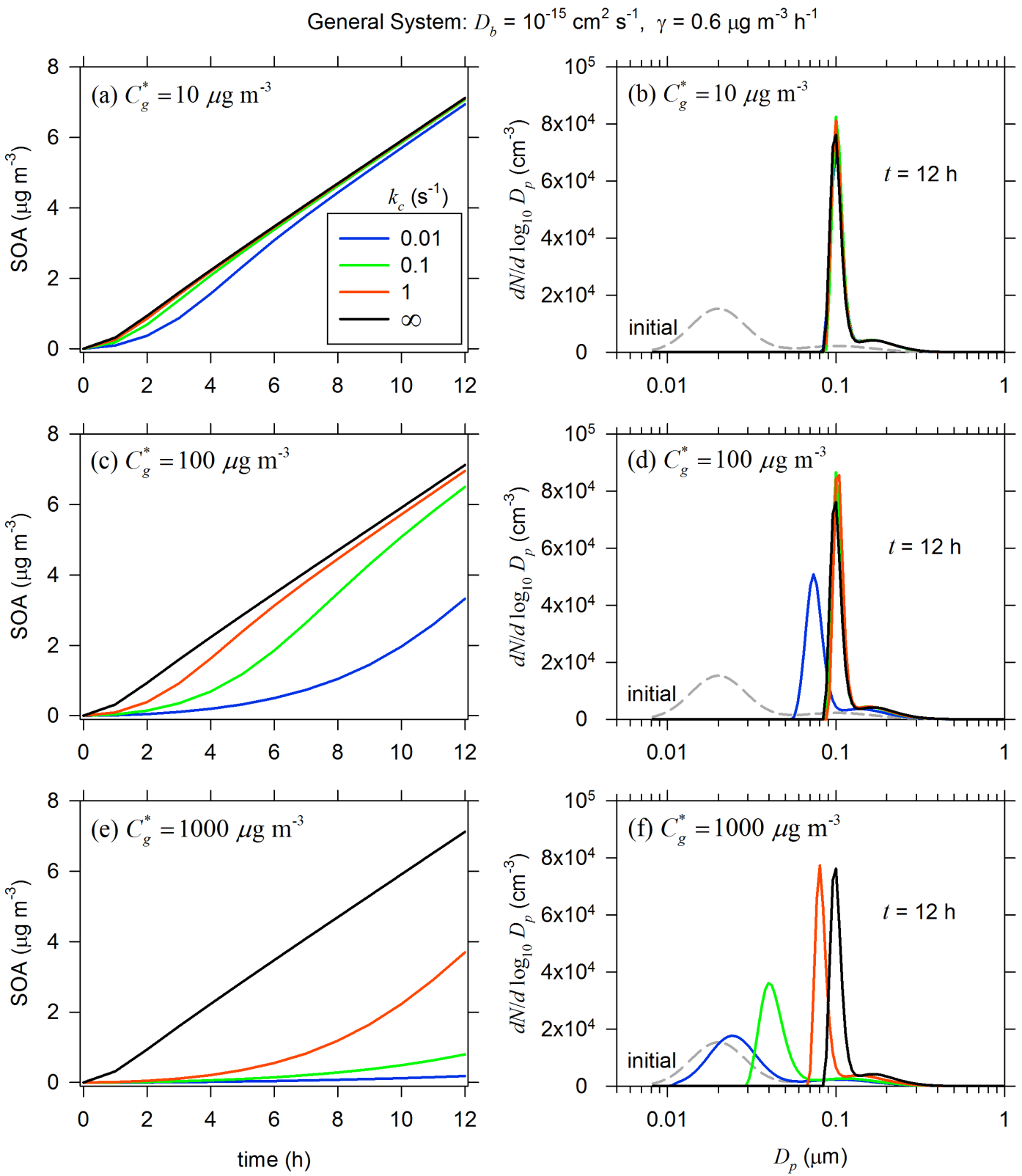

Figure 19. Same as Fig. 18, except $D_{\mathrm{b}}=10^{-15} \mathrm{~cm}^{2} \mathrm{~s}^{-1}$.

tive to the phase state when $D_{\mathrm{b}}$ is about $10^{-13} \mathrm{~cm}^{2} \mathrm{~s}^{-1}$ or less. At $D_{\mathrm{b}}=10^{-15} \mathrm{~cm}^{2} \mathrm{~s}^{-1}$ and $k_{\mathrm{c}}=0.01 \mathrm{~s}^{-1}$, the decay timescale ranges from $1 \mathrm{~h}$ for $C_{\mathrm{g}}^{*}=10 \mu \mathrm{g} \mathrm{m}^{-3}$ to about 3 days for $C_{\mathrm{g}}^{*}=1000 \mu \mathrm{g} \mathrm{m}^{-3}$. Consequently, for intermediate volatility solutes $\left(C_{\mathrm{g}}^{*}>1000 \mu \mathrm{g} \mathrm{m}^{-3}\right)$ to partition in appreciable amounts to semisolid SOA via particle-phase reactions, their $k_{\mathrm{c}}$ values need to be $>0.1 \mathrm{~s}^{-1}$.

4. From a practical standpoint, the particle-phase concentration profiles of a solute (with any $C_{\mathrm{g}}^{*}$ ) reacting with $k_{\mathrm{c}}>0.01 \mathrm{~s}^{-1}$ may be assumed to be at steady-state in particles of any size and any phase state. Furthermore, for $k_{\mathrm{c}} \leq 0.1 \mathrm{~s}^{-1}$ and $D_{\mathrm{b}} \geq 10^{-10} \mathrm{~cm}^{2} \mathrm{~s}^{-1}$, the particlephase reaction occurs uniformly through the entire volume of submicron particles. At higher $k_{\mathrm{c}}$ or lower $D_{\mathrm{b}}$ values, the particle-phase concentration profile becomes increasingly nonuniform (i.e., depleted towards the center of the particle) as the particle size increases. As a result, particle-phase reactions in large semisolid particles occur primarily near the surface while in smaller particles the same reactions may still occur through the entire volume. These differences in the diffusionreaction dynamics across the size distribution, and its 
dependence on the particle-phase state, together control the SOA partitioning timescale and the size distribution evolution.

5. Observations of the evolution of the size distribution can provide valuable clues about the underlying mechanisms of SOA formation (Riipinen et al., 2011; Shiraiwa et al., 2013a). However, all three mechanisms, under certain combinations of $C_{\mathrm{g}}^{*}, D_{\mathrm{b}}$, and $k_{\mathrm{c}}$ values, can produce similar-looking aerosol number size distributions. A concerted experimental strategy is therefore necessary to properly constrain these and other key model parameters and effectively evaluate the next generation of SOA models that treat phase-state thermodynamics, particle-phase diffusion and particle-phase reactions.
6. A proper representation of these physicochemical processes and parameters is needed to reliably predict not only the total SOA mass, but also its compositionand number-diameter distributions, which together determine the overall optical and cloud-nucleating properties.

Future model development work entails implementation of comprehensive gas-phase VOC oxidation mechanisms and the key particle-phase reactions that form organic salts, oligomers, hemiacetals, organosulfates, and other high molecular weight oxidation products, which constitute a significant fraction of SOA. At the same time, a computationally efficient treatment for phase transition thermodynamics (including liquid-liquid phase separation) is needed to provide the combined feedbacks of ambient temperature, relative humidity, and particle composition on the bulk diffusivity and reactivity of the absorbed organic solutes. 
Appendix A: Overall gas-side mass-transfer coefficient $K_{\mathbf{g}}$

Flux $F\left(\mathrm{~mol} \mathrm{~cm}^{-2} \mathrm{~s}^{-1}\right)$ of species $i$ across the gas-particle interface can be written in multiple ways depending on the choice of the mass-transfer coefficient:

gas-side mass transfer coefficient:

$F_{i}=k_{\mathrm{g}, i}\left(\bar{C}_{\mathrm{g}, i}-C_{\mathrm{g}, i}^{\mathrm{s}}\right)$,

particle-side mass transfer coefficient:

$F_{i}=k_{\mathrm{p}, i}\left(A_{i}^{\mathrm{s}}-\bar{A}_{i}\right)$,

overall gas-side mass transfer coefficient:

$F_{i}=K_{\mathrm{g}, i}\left(\bar{C}_{\mathrm{g}, i}-S_{i}^{\prime} \bar{A}_{i}\right)$

In Eq. (A3) the term $\left(\bar{C}_{\mathrm{g}, i}-S_{i}^{\prime} \bar{A}_{i}\right)$ is the overall driving force for mass transfer between the bulk gas-phase and the average bulk particle phase, where

$S_{i}^{\prime}=\frac{C_{\mathrm{g}, i}^{*}}{\sum_{j} \bar{A}_{j}}$

In the above equations, $k_{\mathrm{g}}\left(\mathrm{cm} \mathrm{s}^{-1}\right)$ is the gas-side masstransfer coefficient, $k_{\mathrm{p}}\left(\mathrm{cm} \mathrm{s}^{-1}\right)$ is the particle-side masstransfer coefficient, and $K_{\mathrm{g}}\left(\mathrm{cm} \mathrm{s}^{-1}\right)$ is the overall gas-side mass-transfer coefficient.

We can rewrite Eq. (A3) as

$\frac{1}{K_{\mathrm{g}, i}}=\frac{\bar{C}_{\mathrm{g}, i}-S_{i}^{\prime} \bar{A}_{i}}{F_{i}}=\frac{\left(\bar{C}_{\mathrm{g}, i}-C_{\mathrm{g}, i}^{\mathrm{s}}\right)+\left(C_{\mathrm{g}, i}^{\mathrm{s}}-S_{i}^{\prime} \bar{A}_{i}\right)}{F_{i}}$.

Applying Raoult's law at the interface, we get

$C_{\mathrm{g}, i}^{\mathrm{s}}=S_{i}^{\prime} A_{i}^{\mathrm{s}}$

Combining Eqs. (A5) and (A6), we get

$$
\frac{1}{K_{\mathrm{g}, i}}=\frac{\left(\bar{C}_{\mathrm{g}, i}-C_{\mathrm{g}, i}^{\mathrm{s}}\right)}{F_{i}}+\frac{S_{i}^{\prime}\left(A_{i}^{\mathrm{s}}-\bar{A}_{i}\right)}{F_{i}} .
$$

Combining Eqs. (A1), (A2), and (A7), we can relate the overall gas-side mass-transfer coefficient to gas-side and particleside mass-transfer coefficients as

$\frac{1}{K_{\mathrm{g}, i}}=\frac{1}{k_{\mathrm{g}, i}}+\frac{S_{i}^{\prime}}{k_{\mathrm{p}, i}}$

Finally, replacing the flux term in Eq. (19) with Eq. (A3) yields

$\frac{d \bar{A}_{i}}{\mathrm{~d} t}=\frac{3}{R_{\mathrm{p}}} K_{\mathrm{g}, i}\left\{\bar{C}_{\mathrm{g}, i}-\frac{\bar{A}_{i}}{\sum_{j} \bar{A}_{j}} C_{i}^{*}\right\}-k_{\mathrm{c}, i} \bar{A}_{i}$.

\section{Appendix B: Particle-side mass-transfer coefficient $k_{\mathrm{p}}$}

As noted in the main paper, the particle-side film thickness $\delta_{\mathrm{p}}$, and therefore $k_{\mathrm{p}}$ and $K_{\mathrm{g}}$, are not readily known. We estimate these parameters by assuming that under quasi-steadystate conditions, the analytical solution (Eq. 19) and the twofilm theory (Eq. 21) give the same results. Under quasisteady-state conditions, Eq. (19) becomes

$\frac{\mathrm{d} \bar{A}_{i}}{\mathrm{~d} t}=\frac{3}{R_{\mathrm{p}}} k_{\mathrm{g}, i}\left\{\bar{C}_{\mathrm{g}, i}-\frac{S_{i}^{\prime} \bar{A}_{i}}{Q_{i}}\right\}-k_{\mathrm{c}, i} \bar{A}_{i}=0$.

Rearranging Eq. (B1), we have

$\frac{\bar{A}_{i}}{\bar{C}_{\mathrm{g}, i}}=\left(\frac{S_{i}^{\prime}}{Q_{i}}+\frac{k_{\mathrm{c}, i} R_{\mathrm{p}}}{3 k_{\mathrm{g}, i}}\right)^{-1}$

Similarly, assuming quasi-steady-state for Eq. (21), we get

$\frac{\mathrm{d} \bar{A}_{i}}{\mathrm{~d} t}=\frac{3}{R_{\mathrm{p}}} K_{\mathrm{g}, i}\left\{\bar{C}_{\mathrm{g}, i}-S_{i}^{\prime} \bar{A}_{i}\right\}-k_{\mathrm{c}, i} \bar{A}_{i}=0$.

Rearranging Eq. (B3), we have

$\frac{\bar{A}_{i}}{\bar{C}_{\mathrm{g}, i}}=\left(S_{i}^{\prime}+\frac{k_{\mathrm{c}, i} R_{\mathrm{p}}}{3 K_{\mathrm{g}, i}}\right)^{-1}$.

With our assumption that the two approaches produce the same quasi-steady-state solutions, the left-hand sides of Eqs. (B2) and (B4) are equal, so equating their right-hand sides yields

$\frac{S_{i}^{\prime}}{Q_{i}}+\frac{k_{\mathrm{c}, i} R_{\mathrm{p}}}{3 k_{\mathrm{g}, i}}=S_{i}^{\prime}+\frac{k_{\mathrm{c}, i} R_{\mathrm{p}}}{3 K_{\mathrm{g}, i}}$.

Substituting the expression for $K_{\mathrm{g}, i}$ from Eq. (A8) in Eq. (B5), and simplifying the resulting equation for $k_{\mathrm{p}, i}$ yields

$k_{\mathrm{p}, i}=\frac{k_{\mathrm{c}, i} R_{\mathrm{p}}}{3}\left(\frac{Q_{i}}{1-Q_{i}}\right)$.

Substituting the expression for $Q_{i}$ from Eq. (8) in Eq. (B6), we get

$k_{\mathrm{p}, i}=\frac{k_{\mathrm{c}, i} R_{\mathrm{p}}}{q_{i}^{2}}\left(\frac{q_{i} \operatorname{coth} q_{i}-1}{1-Q_{i}}\right)$.

Using $q_{i}^{2}=R_{\mathrm{p}}^{2} k_{\mathrm{c}, i} / D_{\mathrm{b}, i}$ in Eq. (B7) yields

$k_{\mathrm{p}, i}=\frac{D_{\mathrm{b}, i}}{R_{\mathrm{p}}}\left(\frac{q_{i} \operatorname{coth} q_{i}-1}{1-Q_{i}}\right)$.

The particle-side film thickness is then expressed as

$\delta_{\mathrm{p}, i}=R_{\mathrm{p}}\left(\frac{1-Q_{i}}{q_{i} \operatorname{coth} q_{i}-1}\right)$. 
Note that as $k_{\mathrm{c}, i} \rightarrow 0, q_{i} \rightarrow 0$, and $Q_{i} \rightarrow 1$. Taylor's series expansion of Eq. (B8) yields

$k_{\mathrm{p}, i}=\frac{D_{\mathrm{b}, i}}{R_{\mathrm{p}}} \frac{\left(\frac{1}{3}-\frac{q^{2}}{45}+\frac{2 q^{4}}{945}-\ldots\right)}{\left(\frac{1}{15}-\frac{2 q^{2}}{315}+\ldots\right)}$.
Thus, in the limiting case of nonreacting solute $\left(k_{\mathrm{c}, i}=0\right)$, Eq. (B10) reduces to

$k_{\mathrm{p}, i}=5 \frac{D_{\mathrm{b}, i}}{R_{\mathrm{p}}}$. 
Acknowledgements. R. A. Zaveri thanks M. Shiraiwa (Max Planck Institute for Chemistry), A. Zelenyuk, M. Shrivastava (Pacific Northwest National Laboratory), J. Wang (Brookhaven National Laboratory), M. West (University of Illinois at UrbanaChampaign), and A. S. Wexler (University of California, Davis) for stimulating discussions. The authors thank A. Carlton for editing this paper. This research was supported by the US Department of Energy (DOE) Atmospheric System Research (ASR) Program under contract DE-AC06-76RLO 1830 at Pacific Northwest National Laboratory (PNNL). Participation of J. H. Seinfeld in this research was supported by DOE grant DE-SC0006626 and National Science Foundation grant AGS-1057183. PNNL is operated for the US DOE by Battelle Memorial Institute.

Edited by: A. Carlton

\section{References}

Abramson, E., Imre, D., Beránek, J., Wilson, J., and Zelenyuk, A.: Experimental determination of chemical diffusion within secondary organic aerosol particles, Phys. Chem. Chem. Phys., 15, 2983-2991, 2013.

Astarita, G.: Mass Transfer with Chemical Reaction. Elsevier, New York, 1967.

Bird, R. B., Stewart, W. E., and Lightfoot, E. N.: Transport Phenomena (revised 2nd Edn.). John Wiley \& Sons, Inc., Hoboken, NJ, 2007.

Berkemeier, T., Huisman, A. J., Ammann, M., Shiraiwa, M., Koop, T., and Pöschl, U.: Kinetic regimes and limiting cases of gas uptake and heterogeneous reactions in atmospheric aerosols and clouds: a general classification scheme, Atmos. Chem. Phys., 13, 6663-6686, doi:10.5194/acp-13-6663-2013, 2013.

Bowman, F. M., Odum, J. R., and Seinfeld, J. H.: Mathematical model for gas-particle partitioning of secondary organic aerosols, Atmos. Environ., 31, 3921-3931, 1997.

Carlton, A. G. and Turpin, B. J.: Particle partitioning potential of organic compounds is highest in the Eastern US and driven by anthropogenic water, Atmos. Chem. Phys., 13, 10203-10214, doi:10.5194/acp-13-10203-2013, 2013.

Carlton, A. G., Turpin, B. I., Altieri, K. E., Seitzinger, S. P., Mathur, R., Roselle, S. J., and Weber, R. J.: CMAQ model performance enhanced when in-cloud secondary organic aerosol is included: comparisons of organic carbon predictions with measurements, Environ. Sci. Technol., 42, 8798-8802, 2008.

Carslaw, H. S. and Jaeger, J. C.: Conduction of Heat in Solids, 2nd ed., Clarendon Press, Oxford, 1959.

Crank, J.: The Mathematics of Diffusion, 2nd ed., Oxford University Press Inc., New York, 1975.

Danckwerts, P. V.: Absorption and simultaneous diffusion and chemical reaction into particles of various shapes and into falling drops, Trans. Faraday Soc., 47, 1014-1023, 1951.

Donahue, N. M., Trump, E. R., Pierce, J. R., and Riipinen, I.: Theoretical constraints on pure vapor-pressure driven condensation of organics to ultrafine particles, Geophys. Res. Lett., 38, L16801, doi:10.1029/2011GL048115, 2011.

Doraiswamy, L. K. and Sharma, M. M.: Heterogeneous Reactions: Analysis, Examples, and Reactor Design, Vol. 2.: Fluid-FluidSolid Reactions. Wiley-Interscience, New York, 1984.
Dusek, U., Frank, G. P., Hildebrandt, L., Curtius, J., Schneider, J., Walter S., Chand, D., Drewnick, F., Hings, S., Jung, D., Borrmann, S., and Andreae, M. O.: Size matters more than chemistry for cloud-nucleating ability of aerosol particles, Science, 312, 1375-1378, 2006.

Ervens, B. and Volkamer, R.: Glyoxal processing by aerosol multiphase chemistry: towards a kinetic modeling framework of secondary organic aerosol formation in aqueous particles, Atmos. Chem. Phys., 10, 8219-8244, doi:10.5194/acp-10-8219-2010, 2010.

Ervens, B., Carlton, A. G., Turpin, B. J., Altieri, K. E., Kreidenweis, S. M., and Feingold, G.: Secondary organic aerosol yields from cloud-processing of isoprene oxidation products, Geophys. Res. Lett., 35, L02816, doi:10.1029/2007GL031828, 2008.

Gao, S., Ng, N. L., Keywood, M., Varutbangkul, V., Bahreini, R., Nenes, A., He, J., Yoo, K. Y., Beauchamp, J. L., Hodyss, R. P., Flagan, R. C., and Seinfeld, J. H.: Particle phase acidity and oligomer formation in secondary organic aerosol, Environ. Sci. Technol., 38, 6582-6589, 2004.

Gunthe, S. S., King, S. M., Rose, D., Chen, Q., Roldin, P., Farmer, D. K., Jimenez, J. L., Artaxo, P., Andreae, M. O., Martin, S. T., and Pöschl, U.: Cloud condensation nuclei in pristine tropical rainforest air of Amazonia: size-resolved measurements and modeling of atmospheric aerosol composition and $\mathrm{CCN}$ activity, Atmos. Chem. Phys., 9, 7551-7575, doi:10.5194/acp-9-75512009, 2009.

Gunthe, S. S., Rose, D., Su, H., Garland, R. M., Achtert, P., Nowak, A., Wiedensohler, A., Kuwata, M., Takegawa, N., Kondo, Y., Hu, M., Shao, M., Zhu, T., Andreae, M. O., and Pöschl, U.: Cloud condensation nuclei $(\mathrm{CCN})$ from fresh and aged air pollution in the megacity region of Beijing, Atmos. Chem. Phys., 11, 1102311039, doi:10.5194/acp-11-11023-2011, 2011.

Hall, W. A. and Johnston, M. V.: Oligomer content of $\alpha$-pinene secondary organic aerosol, Aerosol Sci. Technol, 45, 37-45, 2011.

Heaton, K. J., Dreyfus, M. A., Wang, S., and Johnston, M. V.: Oligomers in the early stage of biogenic secondary organic aerosol formation and growth, Environ. Sci. Technol., 41, 61296139, 2007.

Hoyle, C. R., Boy, M., Donahue, N. M., Fry, J. L., Glasius, M., Guenther, A., Hallar, A. G., Hartz, K. H., Petters, M. D., Petaja, T., Rosenoern, T., and Sullivan, A. P.: A review of the anthropogenic influence on biogenic secondary organic aerosol, Atmos. Chem. Phys., 11, 321-343, doi:10.5194/acp-11-321-2011, 2011.

Kalberer, M., Paulsen, D., Sax, M., Steinbacher, M., Dommen, J., Prevot, A. S. H., Fisseha, R., Weingartner, E., Frankevich, V., Zenobi, R., and Baltensperger, U.: Identification of polymers as major components of atmospheric organic aerosols, Science, 303, 1659-1662, 2004.

Kuang, C., Chen, M., Zhao, J., Smith, J., McMurry, P. H., and Wang, J.: Size and time-resolved growth rate measurements of 1 to 5 $\mathrm{nm}$ freshly formed atmospheric nuclei, Atmos. Chem. Phys., 12, 3573-3589, doi:10.5194/acp-12-3573-2012, 2012.

Kulmala, M., Vehkamäki, H., Petäjä, T., Dal Maso, M., Lauri, A., Kerminen, V. M., Birmili, W., and McMurry, P. H.: Formation and growth rates of ultrafine atmospheric particles: a review of observations, J. Aerosol Sci., 35, 143-176, 2004.

Kroll, J. H. and Seinfeld, J. H.: Chemistry of secondary organic aerosol: Formation and evolution of low-volatility organics in the atmosphere, Atmos. Environ., 42, 3593-3624, 2008. 
Lewis, W. K. and Whitman, W. G.: Principles of gas absorption, Ind. Eng. Chem., 16, 1215-1220, 1924.

Liu, A. T., Zaveri, R. A., and Seinfeld, J. H.: Technical Note: Analytical solution for transient partitioning and reaction of a condensing vapor species in a droplet, Atmos. Environ., 89, 651654, 2014.

Liu, Y., Monod, A., Tritscher, T., Praplan, A. P., DeCarlo, P. F., Temime-Roussel, B., Quivet, E., Marchand, N., Dommen, J., and Baltensperger, U.: Aqueous phase processing of secondary organic aerosol from isoprene photooxidation, Atmos. Chem. Phys., 12, 5879-5895, doi:10.5194/acp-12-5879-2012, 2012.

Mouchel-Vallon, C., Brauer, P., Camredon, M., Valorso, R., Madronich, S., Herrmann, H., and Aumont, B.: Explicit modeling of volatile organic compounds partitioning in the atmospheric aqueous phase, Atmos. Chem. Phys., 13, 1023-1037, doi:10.5194/acp-13-1023-2013, 2013.

Nozière, B., Dziedzic, P., and Córdova, A.: Formation of secondary light-absorbing "fulvic-like" oligomers: A common process in aqueous and ionic atmospheric particles?, Geophys. Res. Lett., 34, L21812, doi:10.1029/2007GL031300, 2007.

Paasonen, P., Nieminen, T., Asmi, E., Manninen, H. E., Petäjä, T., Plass-Dülmer, C., Flentje, H., Birmili, W., Wiedensohler, A., Hõrrak, U., Metzger, A., Hamed, A., Laaksonen, A., Facchini, M. C., Kerminen, V.-M., and Kulmala, M.: On the roles of sulphuric acid and low-volatility organic vapours in the initial steps of atmospheric new particle formation, Atmos. Chem. Phys., 10, 11223-11242, doi:10.5194/acp-10-11223-2010, 2010.

Pankow, J. F.: An absorption model of gas/particle partitioning of organic compounds in the atmosphere, Atmos. Environ., 28, 185-188, 1994.

Parikh, H. M., Carlton, A. G., Vizuete, W., and Kamens, R. M.: Modeling secondary organic aerosol using a dynamic partitioning approach incorporating particle aqueous-phase chemistry, Atmos. Environ., 45, 1126-1137, 2011.

Perraud, V., Bruns, E. A., Ezell, M. J., Johnson, S. N., Yu, Y., Alexander, M. L., Zelenyuk, A., Imre, D., Chang, W. L., Dabdub, D., Pankow, J. F., and Finlayson-Pitts, B. J.: Nonequilibrium atmospheric secondary organic aerosol formation and growth, Proc. Nat. Acad. Sci. USA, 109, 2836-2841, 2012.

Pierce, J. R., Riipinen, I., Kulmala, M., Ehn, M., Petäjä, T., Junninen, H., Worsnop, D. R., and Donahue, N. M.: Quantification of the volatility of secondary organic compounds in ultrafine particles during nucleation events, Atmos. Chem. Phys., 11, 90199036, doi:10.5194/acp-11-9019-2011, 2011.

Pierce, J. R., Leaitch, W. R., Liggio, J., Westervelt, D. M., Wainwright, C. D., Abbatt, J. P. D., Ahlm, L., Al-Basheer, W., Cziczo, D. J., Hayden, K. L., Lee, A. K. Y., Li, S.-M., Russell, L. M., Sjostedt, S. J., Strawbridge, K. B., Travis, M., Vlasenko, A., Wentzell, J. J. B., Wiebe, H. A., Wong, J. P. S., and Macdonald, A. M.: Nucleation and condensational growth to $\mathrm{CCN}$ sizes during a sustained pristine biogenic SOA event in a forested mountain valley, Atmos. Chem. Phys., 12, 3147-3163, doi:10.5194/acp-12-3147-2012, 2012.

Pöschl, U., Rudich, Y., and Ammann, M.: Kinetic model framework for aerosol and cloud surface chemistry and gas-particle interactions - Part 1: General equations, parameters, and terminology, Atmos. Chem. Phys., 7, 5989-6023, doi:10.5194/acp-75989-2007, 2007.
Renbaum-Wolff, L., Grayson, J. W., Bateman, A. P., Kuwata, M., Sellier, M., Murray, B. J., Shilling, J. E., Martin, S. T., and Bertram, A. K.: Viscosity of $\alpha$-pinene secondary organic material and implications for particle growth and reactivity, Proc. Nat. Acad. Sci. USA, 110, 8014-8019, doi:10.1073/pnas.1219548110, 2013.

Riipinen, I., Pierce, J. R., Yli-Juuti, T., Nieminen, T., Häkkinen, S., Ehn, M., Junninen, H., Lehtipalo, K., Petäjä, T., Slowik, J., Chang, R., Shantz, N. C., Abbatt, J., Leaitch, W. R., Kerminen, V.-M., Worsnop, D. R., Pandis, S. N., Donahue, N. M., and Kulmala, M.: Organic condensation: a vital link connecting aerosol formation to cloud condensation nuclei (CCN) concentrations, Atmos. Chem. Phys., 11, 3865-3878, doi:10.5194/acp-11-38652011, 2011.

Riipinen, I., Yli-Juuti, T., Pierce, J. R., Petäjä , T., Worsnop, D. R., Kulmala, M., and Donahue, N. M.: The contribution of organics to atmospheric nanoparticle growth, Nature Geoscience, 5, 453-458, 2012.

Saathoff, H., Naumann, K. -H., Mohler, O., Jonsson, A. M., Hallquist, M., Kiendler-Scharr, A., Mentel, Th. F., Tillmann, R., and Schurath, U.: Temperature dependence of yields of secondary organic aerosols from the ozonolysis of a-pinene and limonene, Atmos. Chem. Phys., 9, 1551-1577, doi:10.5194/acp-9-1551-2009, 2009.

Seinfeld, J. H. and Pandis, S. N.: Atmospheric Chemistry and Physics: From Air Pollution to Climate Change (2nd Edn.). John Wiley \& Sons, Inc., Hoboken, NJ, 2006.

Schwartz, S. E. and Freiberg, J. E.: Mass-transport limitation to the rate of reaction of gases in liquid droplets: application to oxidation of $\mathrm{SO}_{2}$ in aqueous solutions. Atmos. Environ., 15, 11291144, 1981.

Shi, B. and Seinfeld, J.H: On mass-transport limitation to the rate of reaction of gases in liquid droplets. Atmos. Environ., 22, 24912499, 1991.

Shilling, J. E., Zaveri, R. A., Fast, J. D., Kleinman, L., Alexander, M. L., Canagaratna, M. R., Fortner, E., Hubbe, J. M., Jayne, J. T., Sedlacek, A., Setyan, A., Springston, S., Worsnop, D. R., and Zhang, Q.: Enhanced SOA formation from mixed anthropogenic and biogenic emissions during the CARES campaign, Atmos. Chem. Phys., 13, 2091-2113, doi:10.5194/acp-13-20912013, 2013.

Shiraiwa, M. and Seinfeld, J. H.: Equilibration timescale of atmospheric secondary organic aerosol partitioning, Geophys. Res. Lett., 39, L24801, doi:10.1029/2012GL054008, 2012 b.

Shiraiwa, M., Pfrang, C., Koop, T., and Pöschl, U.: Kinetic multilayer model of gas-particle interactions in aerosols and clouds (KM-GAP): linking condensation, evaporation, and chemical reactions of organics, oxidants and water. Atmos. Chem. Phys., 12, 2777-2794, doi:10.5194/acp-12-2777-2012, 2012a.

Shiraiwa, M., Yee, L. D., Schilling, K. A., Loza, C. L., Craven, J. S., Zuend, A., Ziemann, P. J., and Seinfeld, J. H.: Size distribution dynamics reveal particle-phase chemistry in organic aerosol formation, Proc. Nat. Acad. Sci. USA, 110, 11746-11750, 2013 a.

Shiraiwa, M., Zuend, A., Bertram, A. K., and Seinfeld, J. H.: Gasparticle partitioning of atmospheric aerosols: interplay of physical state, non-ideal mixing and morphology, Phys. Chem. Chem. Phys., 15, 11441-11453, 2013b. 
Simmel, M. and Wurzler, S.: Condensation and activation in sectional cloud microphysical models, Atmos. Res., 80, 218-236, 2006.

Smith, J. N., Dunn, M. J., VanReken, T. M., Iida, K., Stolzenburg, M. R., McMurry, P. H., and Huey, L. G.: Chemical composition of atmospheric nanoparticles formed from nucleation in Tecamac, Mexico: Evidence for an important role for organic species in nanoparticle growth, Geophys. Res. Lett., 35, L04808, doi:10.1029/2007GL032523, 2008.

Surratt, J. D., Kroll, J. H., Kleindienst, T. E., Edney, E. O., Claeys, M., Sorooshian, A., Ng, N. L., Offenberg, J. H., Lewandowski, M., Jaoui, M., Flagan, R. C., and Seinfeld, J. H.: Evidence for organosulfates in secondary organic aerosol, Environ. Sci. Technol., 41, 517-527, 2007.

Tolocka, M., Jang, M., Ginter, J. M., Cox, F. J., Kamens, R. M., and Johnston, M. V.: Formation of oligomers in secondary organic aerosol, Environ. Sci. Technol., 38, 1428-1434, 2004.

Vaden, T. D., Imre, D., Beránek, J., Shrivastava, M., and Zelenyuk, A.: Evaporation kinetics and phase of laboratory and ambient secondary organic aerosol, Proc. Nat. Acad. Sci. USA, 108, 2190-2195, 2011.

Virtanen, A., Joutsensaari, J., Koop, T., Kannosto, J., Yli-Pirila, P., Leskinen, J., Makela, J. M., Holopainen, J. K., Poschl, U., Kulmala, M., Worsnop, D. R., and Laaksonen, A.: An amorphous solid state of biogenic secondary organic aerosol particles, Nature, 467, 824-827, 2010.

Wang, L., Khalizov, A. F., Zheng, J., Xu, W., Ma, Y., Lal, V., and Zhang, R.: Atmospheric nanoparticles formed from heterogeneous reactions of organics, Nature Geoscience, 3, 238-242, 2010.

Weber, R. J., Sullivan, A. P., Peltier, R. E., Russell, A., Yan, B., Zheng, M., de Gouw, J., Warneke, C., Brock, C., Holloway, J. S., Atlas, E. L., and Edgerton, E.: A study of secondary organic aerosol formation in the anthropogenic-influenced southeastern United States, J. Geophys. Res. Atmos., 112, D13302, doi:10.1029/2007jd008408, 2007.

Winkler, P. M., Ortega, J., Karl, T., Cappellin, L., Friedli, H. R., Barsanti, K., McMurry, P. H., and Smith, J. N.: Identification of the biogenic compounds responsible for sizedependent nanoparticle growth, Geophys. Res. Lett., 39, L20815, doi:10.1029/2012GL053253, 2012.

You, Y., Renbaum-Wolff, L., Carreras-Sospedra, M., Hanna, S. J., Hiranuma, N., Kamal, S., Smith, M. L., Zhang, X., Weber, R. J., Shilling, J. E., Dabdub, D., Martin, S. T., and Bertram, A. K.: Images reveal that atmospheric particles can undergo liquidliquid phase separations, Proc. Nat. Acad. Sci. USA, 109, 13188 13193, 2012.
Zaveri, R. A.: Development and evaluation of a comprehensive tropospheric chemistry model for regional and global applications, Ph.D. thesis, Virginia Polytech. Inst. and State Univ., Blacksburg, Virginia, 1997.

Zaveri, R. A., Easter, R. C., Fast, J. D., and Peters, L. K.: Model for Simulating Aerosol Interactions and Chemistry (MOSAIC), J. Geophys. Res., 113, D13204, doi:10.1029/2007JD008782, 2008.

Zaveri, R. A., Berkowitz, C. M., Brechtel, F. J., Gilles, M. K., Hubbe, J. M., Jayne, J. T., Kleinman, L. I., Laskin, A., Madronich, S., Onasch, T. B., Pekour, M., Springston, S. R., Thornton, J. A., Tivanski, A. V., and Worsnop, D. R.: Nighttime chemical evolution of aerosol and trace gases in a power plant plume: Implications for secondary organic nitrate and organosulfate aerosol formation, $\mathrm{NO}_{3}$ radical chemistry, and $\mathrm{N}_{2} \mathrm{O}_{5}$ heterogeneous hydrolysis, J. Geophys. Res., 115, D12304, doi:10.1029/2009JD013250, 2010.

Zhang, Q., Jimenez, J. L., Canagaratna, M. R., Allan, J. D., Coe, H., Ulbrich, I., Alfarra, M. R., Takami, A., Middlebrook, A. M., Sun, Y. L., Dzepina, K., Dunlea, E., Docherty, K., DeCarlo, P. F., Salcedo, D., Onasch, T., Jayne, J. T., Miyoshi, T., Shimono, A., Hatakeyama, S., Takegawa, N., Kondo, Y., Schneider, J., Drewnick, F., Borrmann, S., Weimer, S., Demerjian, K., Williams, P., Bower, K., Bahreini, R., Cottrell, L., Griffin, R. J., Rautiainen, J., Sun, J. Y., Zhang, Y. M., and Worsnop, D. R.: Ubiquity and dominance of oxygenated species in organic aerosols in anthropogenically-influenced Northern Hemisphere mid-latitudes, Geophys. Res. Lett., 34, L13801, doi:10.1029/2007GL029979, 2007.

Zhang, X., Pandis, S. N., and Seinfeld, J. H.: Diffusion-limited versus quasi-equilibrium aerosol growth, Aerosol Science and Technology, 46, 874-885, doi:10.1080/02786826.2012.679344, 2012.

Ziemann, P. J. and Atkinson, R.: Kinetics, products, and mechanisms of secondary organic aerosol formation, Chem. Soc. Rev., 41, 6582-6605, 2012.

Zobrist, B., Soonsin, V., Luo, B. P., Krieger, U. K., Marcolli, C., Peter, T., and Koop, T.: Ultra-slow water diffusion in aqueous sucrose glasses, Phys. Chem. Chem. Phys., 13, 3514-3526, doi:10.1039/C0CP01273D, 2011. 